\title{
CHILD SEX OFFENDERS' COGNITIVE DISTORTIONS AND RELATED PERSONALITY TRAITS
}

\author{
by \\ Jennifer Joyce Jones \\ A thesis \\ submitted to \\ Victoria University of Wellington \\ in fulfilment \\ of the requirements for the degree \\ of \\ Master of Science \\ in Psychology
}

Victoria University of Wellington

2008 


\title{
Child Sex Offenders' Cognitive Distortions and Related Personality Traits
}

\begin{abstract}
Research has identified that child sex offenders hold thematically distinct cognitive distortions, which Ward and Keenan (1999) call Implicit Theories. The aim of the study was to investigate the relationship between offenders' Implicit Theories and their personality related cognitions. The variables were measured using the Implicit Theory Questionnaire and Millon's (1990) MCMIIII personality scales. Participants comprised 28 male child sex offenders serving a custodial sentence in New Zealand, who elected to have treatment. Majority of participants' personality scale scores reached the clinical threshold. Results identified dependant, depressive and schizoidal personality traits to significantly correlate with three Implicit Theories. Significant personality scale score differences were also revealed between Maori and NZ/European offenders. Clinical and theoretical implications are discussed.
\end{abstract}

Jennifer Jones

Victoria University of Wellington

2008 


\section{Acknowledgements}

I would like to acknowledge and thank the following organisations and individuals who contributed to and supported this research. My friends and colleagues at the New Zealand Department of Corrections (Head Office) for their support and approval of this study; the staff at Te Piriti special treatment unit, with special thanks to Dr. Jim Van Rensburg and Jemma Russell together with Kia Marama special treatment unit staff, Bronwyn Rutherford, Kathy McCann and Karla Matson; Dr Marc Wilson for his assistance and support of the data analyses; and Dr Jim Vess for imparting his clinical knowledge and supervision of this study. Finally, thank you to PJ for the encouragement and unwavering support. 


\section{Table of Contents}

1.0 Child Sex Offenders - Who Are They?.................................................... 8

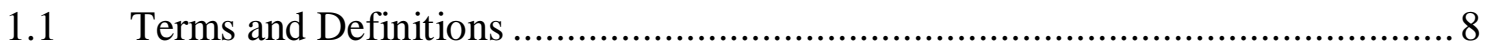

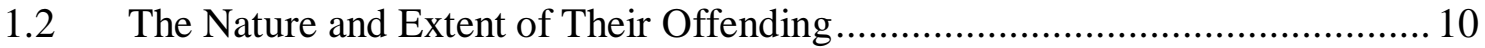

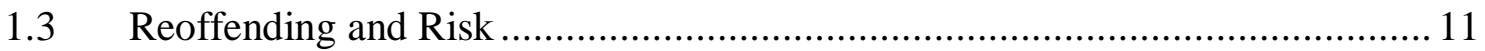

1.4 What Do We Know About Child Sex Offenders' Characteristics? ................... 12

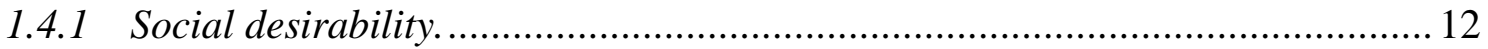

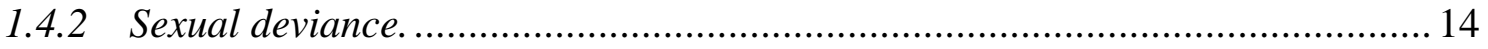

1.4.3 Attachment, intimacy deficits and loneliness. .............................................. 15

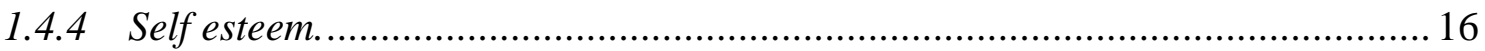

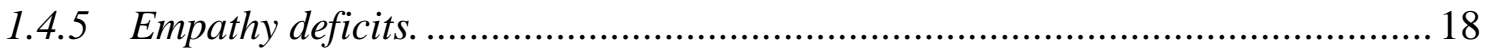

2.0 Cognitive Distortion Review ................................................................... 20

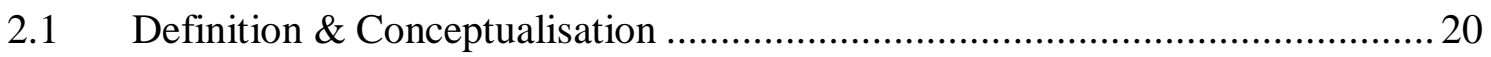

2.2 Cognitive Distortion Hypothesis .................................................................. 21

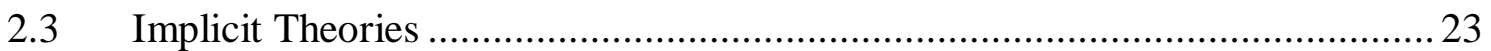

2.4 Ward and Keenan's Five Implicit Theories ....................................................2 25

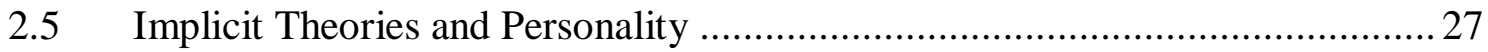

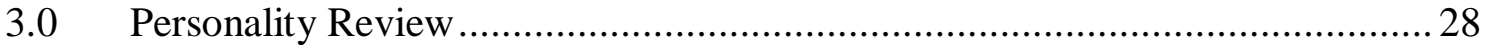

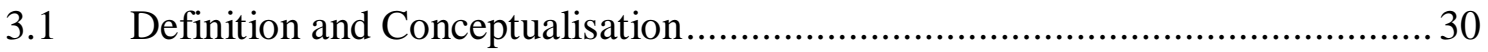

3.2 Millon's Evolutionary Model of Personality and Personality Disorders ........... 31

3.3 Beck's Cognitive Theory of Personality and Personality Disorders .................. 34

3.4 What Role Does Personality Play in Child Sex Offending Theory?.................. 39

3.5 Perceiving, Feeling, Thinking and Coping in Child Sex Offenders.................. 40

3.6 Empirical Review of Personality Disorders in Child Sex Offenders ................. 43

3.6.1 Personality disorder prevalence in child sex offenders and 'normal' populations. 43 
3.6.2 Personality disorders in child sex offenders and other offender populations. ... 44

3.6.3 Personality disorders within the child sex offender population. .......................46

3.6.4 Distribution of personality disorders in New Zealand ethnicity groups. ........... 48

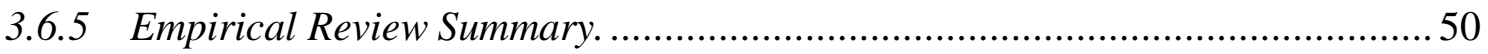

3.7 The Relationship Between Personality Traits and Child Sex Offenders'

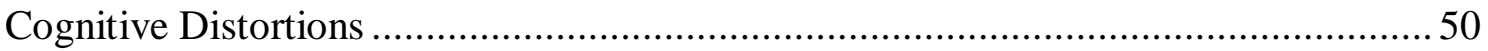

3.8 Framework and Hypotheses for the Present Study ...................................... 51

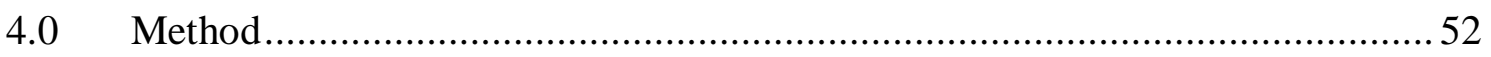

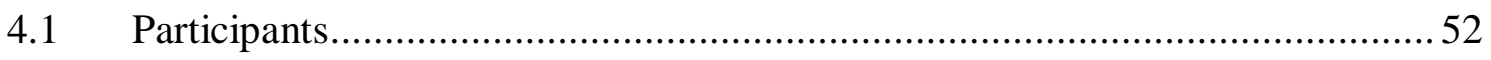

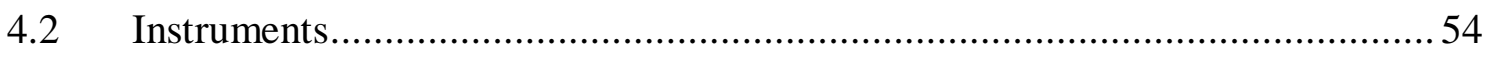

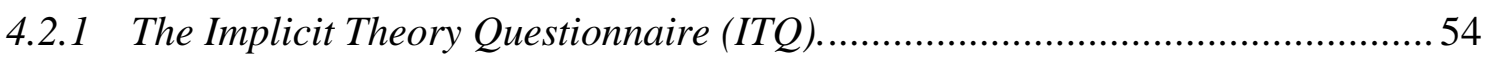

4.2.2 The Millon Clinical Multiaxial Inventory (MCMI-III) ....................................55

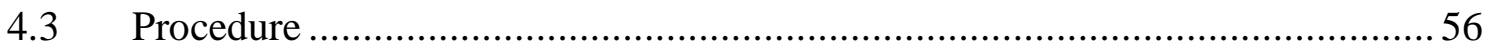

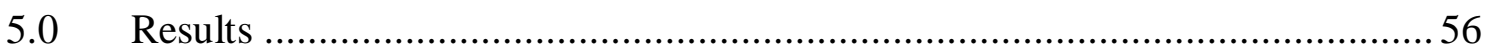

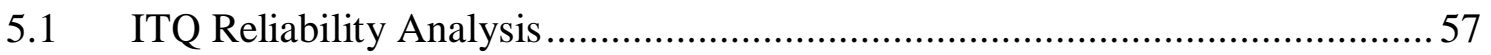

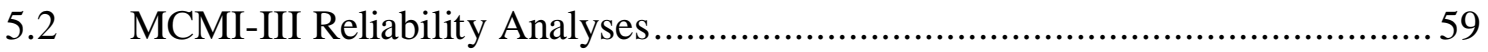

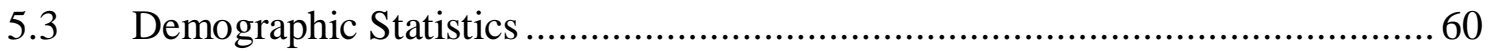

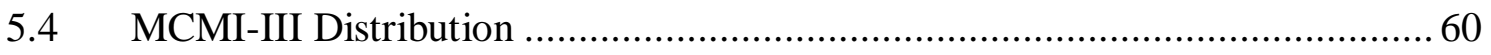

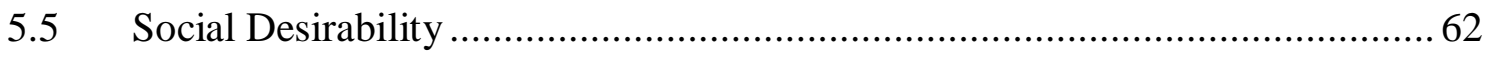

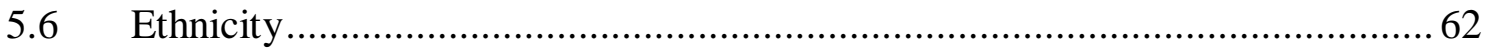

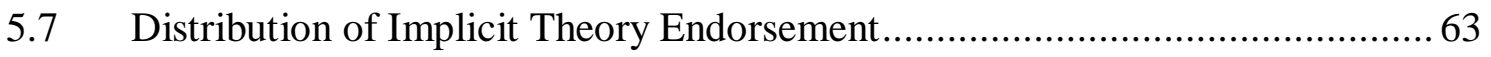

5.8 Implicit Theory \& Personality Trait Score Correlations ................................ 65

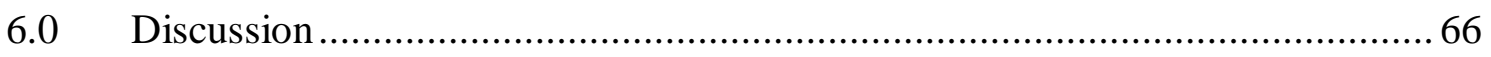

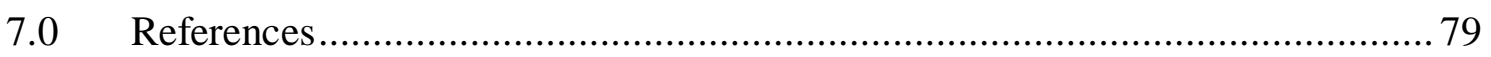




\section{List of Tables}

Table 1. Millon's personality disorder classification matrix 32

Table 2. Beck's cognitive profiles for the personality disorders 37

Table 3. Implicit Theory Questionnaire (ITQ) subscales \& example items..... .55

Table 4. Cronbach's alpha coefficients for each Implicit Theory subscale. .58

Table 5. Correlations between Implicit Theory subscales ..... 59

Table 6. Ethnicity breakdown of participant sample 60

Table 7. MCMI-III mean scores, standard deviations \& correlation coefficients with desirability scores.....

Table 9. Mean endorsement scores and standard deviations according to each Implicit Theory 


\section{List of Figures}

Figure 1. Distribution of MCMI-III personality scale scores as a function of ethnicity 63

Figure 2. Distribution of Implicit Theory endorsement as a function of ethnicity .64 


\author{
Child Sex Offenders' Cognitive Distortions \\ and Related Personality Traits
}

\title{
1.0 Child Sex Offenders - Who Are They?
}

Child sex offenders have been described as a heterogeneous and complex population of individuals (2007). As a group, they possess individual differences that make understanding them as a subset of the offending population extremely difficult. As Smallbone, Wheaton and Hourigan (2003, p. 51) suggest, child sex offenders are "not easily differentiated from community controls or from non-sexual offenders on a broad range of characteristics". However, what has become very clear is the transcendent nature of this type of offending, whereby the sexual victimisation of children by adults occurs across social categories e.g. socio-economic status, ethnicity, marital status, gender and sexual orientation (Robertiello \& Terry, 2007). Robertiello and Terry (2007) claim the most effective way to decrease the re-offending rate of child sex offenders is to understand their characteristics and motivation for offending. Many different approaches have been explored and developed in an attempt to understand these characteristics and motivational factors. The current research aims to tap into what Robertiello and Terry term 'characteristics and motivation' of child sex offenders. This will be carried out by exploring personality traits and offending beliefs of a New Zealand sample of child sex offenders.

\subsection{Terms and Definitions}

Before embarking on a review of child sex offenders, prominent terms require clarification. A number of authors within the literature refer to the term 'characteristic' as a means to describe personality traits or overall tendencies. For the purposes of this 
study, the term 'characteristic' does not provide a precise enough definition to warrant any interchangeable use with the term 'personality' or 'trait'. Therefore, the term 'characteristic' is employed to describe a broader spectrum of idiosyncratic tendencies, including those that are offence related. Phenomena that are distinctly personality and trait related will be labelled as such. For the purposes of this review, personality and disordered personality are conceptualised as dimensional, whereby traits that are adaptive can be maladaptive at a high baseline level. However, the clinical distinction between personality and disordered personality can only be established via a comprehensive diagnostic process.

An important term used in this review is 'child sex offender'. This term refers to adults (17 years of age and older) who sexually offend, in any manner, against children younger than 16 years of age. Research has identified that adults who engage in sexual contact with children do not necessarily prefer children as their sexual partner (Ward, 2003). Offenders who don't necessarily prefer children as sexual partners, have been classified as 'child molesters' (Feelgood \& Hoyer, 2008). Those who do have an interest or preference for pre-pubescent children are candidates for meeting the criteria for a paraphillic disorder, namely paedophilia. As defined by the DSM-IV-TR (APA, 2000, p.566), paedophilia is where an individual experiences recurrent and intense sexually arousing fantasies, sexual urges or behaviours generally involving prepubescent children.

Bogaerts, Daalder, Vanheule, Desmet \& Leeuw (2008) state the distinction between paedophilia and child molesters in simpler terms, which relates to the individuals' usual sexual preferences. The paedophile is preoccupied with, and has a sexual preference for children, unlike the child molester who prefers adult sexual 
relations but is opportunistic with sexual behaviour with pre or post-pubescent children. For the purposes of this review, the term 'child sex offender' is used as an umbrella term that includes a) those whose sexual preference is pre-pubertal children (paedophiles); and b) those with a sexual preference for adults but will sexually offend against children, both pre or post-pubertal, if the opportunity arises (child molesters). However, where the empirical literature is explicit in the research of either 'paedophiles' or 'child molesters', the distinction will be made. For an in-depth review on child sex offender classification, see Feelgood and Hoyer (2008).

\subsection{The Nature and Extent of Their Offending}

As outlined above, child sex offenders are diverse in their victim preferences and their motivations to offend. Given the nature of their offending: sexual and against a child - they are also hesitant to admit the extent of their offending behaviour. Kaplan (1985) found in her sample of child sex offenders, that as a group they divulged only $5 \%$ of their offending history when interviewed within the justice or correctional setting. Taking into consideration the results of Kaplan's (1985) research, Abel and Rouleau (1990) went to extraordinary lengths to ensure optimal surroundings and confidentiality when they conducted offending history interviews of 561 child sex offenders.

The data collected in Abel and Rouleau's (1990) study uncovered offence histories that would ordinarily remain cloaked. Data relating to victim characteristics showed that $56.1 \%$ of child sex offenders only perpetrated extra-familially (non-family members) and $12 \%$ only perpetrated intra-familially (family members, also referred to as incest). Nearly a quarter $(23.3 \%)$ of their sample admitted to offending both extrafamilially and intra-familially. Abel and Rouleau's results also showed that $67.2 \%$ of 
the sample offended against females, $11.9 \%$ against males and $20 \%$ offended regardless of the victim's gender. More recent studies have identified that between $29 \%$ and $40 \%$ of sampled child sex offenders perpetrated against both male and female children (English, 2003; Heil, 2003). The varying of victim gender (or victim characteristics) is referred to as a 'cross-over' effect (Levenson, Becker, \& Morin, 2008). Levenson etal., (2008) investigated the nature and extent of the 'cross-over' effect using archival data. They found that child sex offenders with victims aged six and under were significantly more likely to 'cross-over' gender and offend against both male and female victims. These offenders have been identified as posing a greater risk of reoffending (Vess \& Skelton, in press).

\subsection{Reoffending and Risk}

Research has established that child sex offenders who offend against male victims are at higher risk of reoffending than those who offend only against female victims. Vess and Skelton (in press) found in their sample of child sex offenders, that overall recidivism rates for those who only offended against female victims was $8 \%$, whereas the overall recidivism rate for those who only offended against male victims was $23 \%$. Their results identified that the child sex offenders who chose to sexually offend against females were more likely to re-offend against females, albeit at a low overall recidivism rate. Those who sexually offended against male victims were at higher risk of re-offending by comparison.

In the not too distant past, child sex offenders were believed to be specialist offenders, whereby their sole criminal repertoire was sexual offences against children. Research conducted by Smallbone et al., (2003) revealed that intra-familial and extrafamilial child sex offenders commit a wide range of offences, including violent 
offences. Forty-six percent of intra-familial child sex offenders and $62 \%$ of extrafamilial child sex offenders had a record of nonsexual convictions. Smallbone et al.'s data also identified over a third of extra-familial child sex offenders had previous violent convictions compared to $7 \%$ of intra-familial child sex offenders who had previous violent convictions.

Very recently Vess and Skelton (in press) investigated sexual and violent recidivism according to offender type using actuarial risk measurement. Archival data was utilised and an average follow up period for recidivism assessment of 15 years. The recidivism rate for the 1,165 child sex offenders ranged from $6 \%, 15 \%$ and $38 \%$ according to low, medium and high-risk categories, respectively. Seventy-six percent of the offenders who only had a conviction history of sexual offences against a child, went on to re-offend against another child, whereas $17 \%$ went on to sexually reoffend against an adult victim. Similarly, $37 \%$ of adult sex offenders with no previous conviction of child sexual offences went on to commit contact sexual offences against children. These findings suggest that child sex offenders are criminally versatile and more heterogeneous than once thought. Moreover, the assessment of reoffending risk for child sex offenders also needs to incorporate an overarching assessment of criminal attitudes and violence propensity.

\subsection{What Do We Know About Child Sex Offenders' Characteristics?}

\subsubsection{Social desirability.}

Social desirability has been described by Tan and Grace (2008, p. 61) as the "desire to make a favourable impression on others". This tendency, to appear favourably to others, has not only been linked with personality traits within the social psychology literature but also with child sex offenders (Paulhus, 1984). Social 
desirability has been proposed to consist of two factors: self-deception and impression management (Paulhus, 2002). Like it appears, self-deception refers to deception to the self, much like denial, whereas impression management refers to the deception of others. Studies have shown that sampled child sex offenders tend to have higher levels of impression management (deception of others) compared to adult sex offenders and non-sex offenders (Gudjonsson \& Sigurdsson, 2000; Nugent \& Kroner, 1996). Child sex offender subtypes have also revealed differences in socially desirable responding. Intra-familial child sex offenders and non-sexual offenders were observed to have higher levels of socially desirable responding compared to extra-familial child sex offenders (Hayashino, Wurtele, \& Klebe, 1995). The authors did not speculate as to why this may be however, intra-familial child sex offenders may perceive themselves to hold greater social standing within the community by being a parent. Moreover, they stand to lose more than extra-familial offenders in terms of their family unit e.g. spouse and access to their children. In this respect, offenders who sexually offend against their children may respond in a socially desirable manner to ensure retention of their family structure.

Gannon and Polaschek (2005) investigated "faking good" responses in treated and untreated child sex offenders. A computer generated questionnaire provided offence related beliefs statements to treated and untreated child sex offenders together with non-sexual offenders and non-offender community controls. All offender groups and controls tended to disagree with the offence related statements. Response latency was recorded for all groups with shorter response times suggesting a "faking good" response. Their sample of treated child sex offenders responded in less time when they rejected the offence related statements compared to the non-offender controls. They 
interpreted these results as most likely reflecting a practice effect. That is, following intensive cognitive treatment offenders may be more practiced at identifying the "right answer". Conflicting social desirability results are evident within the child sex offender literature. However, what has been established is the propensity for a group of child sex offenders to respond in a socially desirable fashion.

\subsubsection{Sexual deviance.}

An aspect of what child sex offenders attempt to occlude in their socially desirable responding is their deviant sexual preferences, of which, some admit to experiencing from an early age. Research has found that a significant proportion of sampled child sex offenders admitted to experiencing deviant thoughts and fantasies about child victims during their adolescence. Abel \& Rouleau (1990) found that $50 \%$ of extra-familial paedophiles and $40 \%$ of intra-familial paedophiles in their sample reported experiencing deviant sexual interests by the ages 16 and 18 years, respectively. While this may have been brushed aside at the time as youthful experimentation or curiosity, these deviant interests can burgeon into deviant behaviour. Abel, Mittleman and Becker (1984) and Abel and Becker's (1985) studies found that between 50\% and $55 \%$ of sampled child sex offenders admitted to initiating sexual behaviour with a child during their adolescent years.

Some argue that deviant sexual interests are developed as a result of deviant sexual fantasies during a young and formative time in life (Abel et al., 1987; Marshall \& Eccles, 1991). As a result, adolescent child sex offenders have become increasingly targeted within the theoretical and empirical literature. Barbaree, Marshall and McCormack (1998) proposed a theoretical framework to explain the development of sexual deviance. At the cornerstone of their proposition was childhood adversity within 
the family. They argued that familial abuse fostered 'social disabilities' that synergistically set the foundation for abusive sexual behaviour. The syndrome of 'social disabilities' was characterised by insecure attachments, intimacy deficits, low self-esteem, empathy deficits and a level of antisocial behaviour.

\subsubsection{Attachment, intimacy deficits and loneliness.}

Attachment styles and intimacy skill deficits have garnered theoretical and empirical interest within the adult and child sex offending literature (Hudson \& Ward, 1997; Marshall, 1989a, 1989b; Sawle \& Kear-Colwell, 2001; Ward, Keenan, \& Hudson, 2000b). Bowlby $(1969,1973,1980)$, who developed Attachment Theory, claimed that a secure attachment is developed through loving parental interactions beginning at birth. Early traumas in child-parental interactions are purported to have a shaping influence on the future ability to build romantic adult attachments at an emotionally intimate level (Marshall, 1989; Marshall \& Marshall, 2000). Craissati, McClurg, and Browne (2002) found in their study of child sex offenders that nearly half of the sample reported traumatic experiences relating to their own sexual victimisation as a child. Overall, the entire sample of child sex offenders identified a high degree of childhood disruption and maltreatment. Craissati et al.'s findings suggest that childhood maltreatment and trauma in child sex offenders may be an important factor that shapes their ability to securely attach to key figures such as romantic same age partners. Their findings also go towards supporting Barbaree et al.,'s (1998) 'social disability' framework of abusive behaviour.

Marshall (1989a) proposed that an insecure attachment compromises one's capacity to develop and maintain a stable, satisfying romantic relationship. Marshall suggested that the resulting intimacy skill deficits and the presence of emotional 
loneliness is a key factor in the attempt to obtain sexual fulfilment through aggression, or from vulnerable and less threatening partners such as children. The premise is that child sex offenders use sexual behaviour as their method to obtain affection, emotional intimacy and security from those who pose less of a threat of rejection. Studies have shown that sampled child sex offenders typically report a greater degree of emotional loneliness, fear of intimacy and isolation than non-offenders (Fisher, Beech \& Browne, 1999; Marsa et al., 2004; Marshall, 1989a, 1989b; Marshall, Champagne, Brown \& Miller, 1997).

Marsa et al., (2004) found in a sample of child sex offenders that $65 \%$ had a fearful attachment style; $21 \%$ had a preoccupied attachment style; $14 \%$ had a dismissive attachment style, while only $7 \%$ revealed a secure attachment style. Their results also showed that child sex offenders had higher scores of loneliness and external locus of control compared to the community controls, violent offenders and non-violent offenders. Overall, research surrounding attachment style in the sex offending population has important implications for profiling, assessment and treatment. However, the causal factor in the development of an insecure attachment style is thought to be poor primary relationships, i.e. maternal and paternal bonds.

\subsubsection{Self esteem.}

In addition to Barbaree et al.,'s (1998) 'social disability’ framework, Marshall, Cripps, Anderson \& Cortoni (1999) also claimed that low self-esteem is an important etiological factor in child sex offending behaviour that ought to be targeted in the treatment process. Marshall et al., (1999) proposed that the causal relationship between self-esteem and child sex offending is mediated by the offenders' reduced capacity to cope with stress. This in turn triggers the subsequent use of dysfunctional coping 
strategies and the search for more effective ways to cope - e.g. using sex or fantasy and masturbation. The results of their study identified that their sample of child sex offenders used emotion-focussed coping, compared to problem-focussed coping. Problem-focussed coping relies heavily on logic and the ability to reason and reflect on the situation. Emotion-focussed coping relies solely on how the situation is impacting the individual on an emotional level. The latter coping style is considered to be extremely ineffective in reducing stress (Bijttebier \& Vertommen, 1999).

Also empirically linked with self-esteem are empathy-deficits. Marshall, Hamilton and Fernandez (2001) found in their study that self-esteem was inversely correlated with victim-specific empathy deficits. That is, as empathy scores relating to their victim decrease, self-esteem scores increase. This result shows that increased selfesteem, which ought to be a protective characteristic, is linked with lower levels of victim empathy. The researchers proposed that decreasing victim empathy may serve as a mechanism to protect offenders' "fragile sense of self-worth" (p. 171). In other words, an offender who has a higher level of victim empathy will experience greater levels of negative emotion (e.g. sadness) and cognitive consequences (e.g. guilt, anxiety) following an offence. This in turn will impact negatively on their self-worth and how good they feel about themselves. Marshall et al.,'s results suggest that the less empathy an offender has for their victim, the less likely the offence will elicit negative emotion and a diminishing sense of self-worth. Alternatively, high self-esteem may reflect a set of narcissistic traits e.g. grandiosity, entitlement and limited capacity for empathy. Nevertheless, these results highlight the complex nature of interlocking cognitive offender characteristics. 


\subsubsection{Empathy deficits.}

The lack of empathy that child sex offenders have for their victims is a relatively new area of theoretical and empirical study (Fernandez, Anderson, \& Marshall, 1999; W. L. Marshall et al., 2001; Smallbone et al., 2003; Wood \& Riggs, 2008). Nevertheless, empathy development has been targeted as a key treatment area (Ward, 2003). Group treatment, designed to enhance empathy toward victims, involves identifying immediate effects of their offending along with after effects and long-term consequences for the victim (Ward, 2003). Ward, Polaschek and Beech (2005, p. 209) refer to empathy as "perceiving that another person has been harmed, frightened or otherwise subjected to a negative experience, and the feelings of concern, caring and compassion towards that person”.

Some argue that on a theoretical level, empathy deficits in child sex offenders is a global trait, i.e. offenders show no empathy toward anyone (Marshall \& Barbaree, 1990). However, research has now shown that empathy levels in a sample of child sex offenders were comparable to non-offenders when given child accident victim vignettes (Marshall et al., 2001). Marshall et al.'s results also identified that child sex offenders showed limited empathy towards their own victims and a marked reduction in empathy toward victims of other offenders. This is when compared to a control group of nonoffenders. Implications generated from these results identify that a) empathy may not be a global trait in child sex offenders, since they report empathy towards child accident victims; and b) observed empathy deficits are not specific to the offence process - for example, empathy deficits are observed in a research environment, outside of the offence process - i.e. when measured against their own victim and other offenders' victims. 
Research has also shown an inverse relationship between victim empathy and cognitive distortions, whereby interventions that increase victim empathy also decrease cognitive distortions (Pithers, 1994). When a child sex offender claims that their fouryear-old victim "wanted to be taught about sex", it is quite clear that there is an element of thinking that deviates from societal norms and values. These deviant thoughts have been termed cognitive distortions and refer to the blaming, minimising, excusing and rationalising of sexually abusive behaviour (Ward, 2000). Cognitive distortions, also described as “offence-endorsing statements" (Ward, Gannon, \& Keown, 2006, p. 324), are purported to facilitate and maintain offending behaviour (Gannon, Ward, \& Polaschek, 2004). Cognitive distortions of differing themes have been identified within the literature (Ward \& Keenan, 1999). The complexity of cognitive distortions and their structure have also generated promising theory and empirical data.

Marshall, Anderson \& Fernandez (1999) investigated the proposition that deficits in victim empathy were related to, or a by-product of, cognitive distortions (or offending beliefs), whereby the offender erroneously believes, for example, that sexual contact with a child is not harmful, or is even beneficial. This type of cognitive distortion would prevent an offender from realising that his actions are negative and would constitute harmful behaviour. The results from their sample of child sex offenders indicated that the greatest empathy deficits were in relation to their own victims. Their empathy deficits were also inversely correlated with their cognitive distortion responses. In other words, as their empathy scores decreased, their cognitive distortion levels increased. This further highlights the complex and interlocking cognitive products evident in child sex offenders. 
To date, theory and research has identified critical features that play a role in explaining the initiation and maintenance of child sex offending behaviour. A selection of these includes early trauma and offenders' own sexual victimisation history, deviant sexual preferences, insecure attachment styles, low self-esteem, ineffective coping strategies, empathy deficits and cognitive distortions. Despite the growing literature identifying commonalities within the child sex offender population, there still appears to be considerable heterogeneity. Offence characteristics that have received growing theoretical empirical attention and demonstrated clear heterogeneity are child sex offenders' cognitive distortions. Cognitive distortions are seen as complex and heterogeneous in nature and have been afforded a central role in the facilitation and maintenance of sex offending behaviour Gannon et al., (2004). The current research explores cognitive distortions on a theoretical and empirical level in relation to personality traits in child sex offenders in an attempt to unravel the complexity within the cognitions of child sex offenders.

\subsection{Cognitive Distortion Review}

\subsection{Definition \& Conceptualisation}

Cognitive distortions have been regarded as a critical feature in the etiology of child sex offending behaviour and in the offence process itself (Hall \& Hirschman, 1991, 1992; Marshall \& Barbaree, 1990; Ward \& Seigert, 2002). As a result, challenging cognitive distortions has become a key component in the treatment of child sex offenders and a burgeoning area of theoretical and empirical interest. However, the attempts to define and conceptualise cognitive distortions have met with difficulties. In part, this may be due to their complex nature and utility for the child sex offender.

Numerous issues arise when conceptualising this cognitive phenomenon. A selection of 
these issues includes: are they justificatory self-statements? Are they a product of cognitive dissonance or denial? Or, do they represent a more global belief system? In an early study of cognitive distortions as a concept, Abel, Becker and CunninghamRathner (1984, p. 98), described cognitive distortions as "a set of cognitive beliefs that support sexual involvement with children".

\subsection{Cognitive Distortion Hypothesis}

Abel et al., (1984) were pioneers in the conceptualisation and elaboration of child sex offenders' cognitive distortions. Abel et al. used a Social Learning Theory framework to develop the Cognitive Distortion Hypothesis. It offered an explanation into the etiology of distorted cognitions and their utility within the offence process. The Cognitive Distortion Hypothesis posits that endorsement of child sex offending is developed when adolescent boys do not learn to inhibit their sexual arousal from inappropriate stimuli. Instead, deviant sexual arousal patterns are formed as a result of fantasising during masturbation and orgasm. Without direction by friends or parents to guide appropriate behaviour, adolescents develop into adults with well-established and deviant sexual arousal patterns. The now adult child sex offenders offend in direct violation of societal norms which is where Abel et al., (1984) proposed cognitive distortions emerge.

Abel et al., (1984) suggested that child sex offenders experience a state of cognitive conflict which is generated by the incongruence of their deviant thoughts and/or behaviours, and how these thoughts and behaviours violate social norms. The impact of experiencing this conflict generates aversive levels of anxiety and complex emotions, including shame and guilt. By using Festinger's (1957) Cognitive Dissonance Theory, Abel et al., suggested that child sex offenders distort their 
cognitions to align them with their deviant thoughts, fantasies and behaviour. For example, an individual has sexual contact with a seven-year-old child; he knows this is inappropriate behaviour and is conflicted by this realisation. To mitigate the levels of cognitive distress (shame or guilt), the individual rationalises his offending to appear within the realms of propriety. This may include placing responsibility on the victim, who at the time was wearing a scant swimming costume and "seduced him". Abel et al., proposed that this process alleviates the conflict and subsequent distress by viewing deviant thoughts and behaviours within acceptable limits and relegating the importance of social norms. These cognitive distortions are then drawn upon to continue sexually deviant behaviour.

Abel et al., (1984) suggested that cognitive distortions are strengthened when offenders perceive the presence of positive consequences and/or the absence of negative consequences following their sexual offending behaviour. Abel et al., refers to the offenders' perceived absence of negative consequences for the child. This may be due to the seduction and grooming process (gradual and small increments of inappropriate behaviour) or the child's minimal resistance due to trust or fear due to coercive techniques by the offender. The child's minimal resistance is then perceived as willing and consenting behaviour, thus, confirmation of the offender's cognitive distortions.

Researchers have begun to study the cognitions of child sex offenders to understand this internal experience. Choudhry (1995) investigated and compared the cognitive distortions of intra and extra-familial child sex offenders. The child sex offenders were assessed on their attitudes and beliefs surrounding adult-child sexual interactions. The results showed no significant differences in cognitions that set apart the two types of child sex offenders. Findings from this research were critical in 
identifying that cognitive distortions of child sex offenders are not thematically bound by victim type. In contrast, speculations were made to suggest cognitive distortions are a reflection of something more fundamental to the offender.

\subsection{Implicit Theories}

More recently, Ward (2000) proposed that cognitive distortions stem from underlying maladaptive assumptions or beliefs and the tendency to process perceptually biased information. The proposition of biased perception based on maladaptive beliefs or assumptions parallels the 'Beckian' approach to cognitions through Aaron Beck's Cognitive Theory, which he used to explain and treat depression.

Beck (1963) proposed that individuals suffering from depression develop negative schemas (or beliefs) relating to themselves, others and the world in general. These negative schemas are generated as a result of developmental adversity and are deeply entrenched - which also parallels Barbaree et al.,'s (1998) 'social disability' etiological framework. The negative schemas then provide orienting qualities to negative stimuli and a lens through which processing of neutral information is filtered through (encoded, interpreted and retrieved) as negative. According to Ward (2000), the lens through which child sex offenders perceive their victim and offending behaviour, provides the basis for their distorted cognitions. These maladaptive beliefs, or the lens through which offenders perceive themselves, others and the world in general, has been identified as heterogeneous in nature (Ward \& Keenan, 1999).

More than a decade on from the Cognitive Distortion Hypothesis, Ward and Keenan (1999) provided a new conceptualisation of cognitive distortions using a blend of Social Cognitive Theory and the developmental psychology literature. Ward (2000) claimed that the developmental and social cognition literature provided a framework to 
understand how information is learned and consolidated by the testing of hypotheses in the social environment. Consequently, from an early age knowledge is gathered to make reliable predictions and expectations about the social environment. These predictions and expectations may be dramatically different depending upon the type of parenting and social upbringing a child receives.

Ward and Keenan's (1999) new conceptualisation viewed cognitive distortions as products of a much larger network of interlocking and underlying schemas (or beliefs). Ward (2000) called these beliefs 'Implicit Theories'. More specifically, Implicit Theories are a 'causal-explanatory framework' that produce a network of beliefs or schemas (Ward, Keenan, \& Hudson, 2000a). These beliefs function to explain the actions of others, ourselves, the world in general and assist in developing further predictions and expectations relating to the social environment (Ward \& Keenan, 1999). Unlike Abel et al.'s (1984) Cognitive Distortion Hypothesis that posits cognitive distortions as independent or isolated distorted thoughts, the cognitive distortions generated from Implicit Theories are pervasive, stemming from a larger belief structure. In the context of child sex offenders, specific Implicit Theories are employed to infer the mental state, present behaviour and future behaviours of their victim's together with their victim's beliefs, desires and attitudes (Ward \& Keenan, 1999).

Child sex offenders' cognitive distortions are diverse in nature and purpose and can range from beliefs that are offence endorsing (e.g. "sexual activities with a child is beneficial") to those that relinquish culpability (e.g. "I was drunk when it happened"). Marziano, Ward, Beech and Pattison (2006) examined the cognitive distortions in child sex offenders' offence narratives to identify thematically distinct distortions that clustered together to form a larger belief network - specifically, an Implicit Theory. 
The results of their qualitative analyses identified five distinct clusters of cognitive distortions that comprised five Implicit Theories. Each Implicit Theory offered a different schematic theme including: children as sexual objects, entitlement, dangerous world, uncontrollability and nature of harm.

\subsection{Ward and Keenan's Five Implicit Theories}

Marziano et al., (2006) described child sex offenders who hold the children as sexual beings Implicit Theory, to believe that children both enjoy and desire the pleasure that comes from sexual connection. Also, that children have the capacity to make informed decisions about sexual behaviour. These offenders also believe that sexual contact with children is unlikely to be harmful but in fact, beneficial for the child (Ward \& Keenan, 1999). Sanctioning this experience is viewed as denying offenders' and their victims' natural expression of sexuality. Cognitive distortions generated by this Implicit Theory may include "children are curious about sex and enjoy it" and "she was trying to arouse me by walking in front of me with skimpy clothes on".

Offenders who hold the Entitlement Implicit Theory are suggested by Marziano et al., (2006) to believe they are in a superior category than others. This places them in a position of special consideration and treatment. Due to this special status, offenders believe their sexual needs deserve to be met by whomever and whenever they desire. Ward and Keenan (1999) suggest that child sex offenders holding the Entitlement Implicit Theory are above laws and morals which ought to be acknowledged by others who hold a lower status. Child sex offenders view their victims as being fulfilled by being the provider of their sexual needs and perversely, by being controlled and dominated. However, child sex offenders' tendency to take their victims experience into consideration is for secondary gain only (Ward \& Keenan, 1999). Cognitive 
distortions generated by this Implicit Theory may include "people do what I tell them and that includes sex" and "men are entitled to have sex with whomever they like whenever they like".

According to Ward and Keenan (1999), there are two strands to the Dangerous World Implicit Theory. The first strand emphasises the offenders' need to assert their dominance and control over others to ensure their status or position is strengthened. This can involve punishment or retribution against others who are perceived to have harmed them in some way. Ward and Keenan (1999) claim that punishment can involve the sexual abuse of a child as retribution for perceived wrongs by their mother. Another key feature of the first strand is that child sex offenders believe the world and those in it to be inherently hostile (Marziano et al., 2006). Cognitive distortions generated by this implicit theory may include "I did it to get revenge on her and her mother".

The second strand of the Dangerous World Implicit Theory emphasises the offenders' view that the world is a threatening place. A key feature is the offenders' belief that adults are threatening, untrustworthy and rejecting while children are more dependable, acceptable and less likely to take unfair advantage (Ward \& Keenan, 1999). Unlike the retributive stance of the first strand, child sex offenders holding the beliefs from the second strand do not perceive themselves as capable to retaliate against others. Cognitive distortions generated by this implicit theory may include "you can’t trust adults" and "kids really know how to love you".

Offenders who hold the Uncontrollability Implicit Theory believe that the world, including events, emotions, sexual feelings and thoughts are uncontrollable (Ward \& Keenan, 1999). Ward and Keenan claim that exposure to traumatic events such as a 
death of a parent or sexual abuse is likely to generate the feeling of no control over the world and others. Cognitive distortions generated by this implicit theory may include "I was high on drugs and alcohol at the time" and "I did it because I was sexually abused as a child" "Some people are not 'true' child molesters - they are just out of control and made a mistake".

The key belief related to the Nature of Harm Implicit Theory is that harm is on a dimension of severity and that sexual contact is beneficial and unlikely to cause any harm. Offenders believe that harm to the child depends on circumstances. This can be due to the offenders' perception that without the use of force, penetration or if the child was asleep at the time and is unaware of what is taking place, the child goes unharmed. The belief that sex is inherently pleasurable and thus beneficial drives the second perception. Cognitive distortions generated by this implicit theory may include "we were only touching, it wasn't really sex" or "if something is enjoyable, how can it be harmful?"

\subsection{Implicit Theories and Personality}

Much like Ward (2000), Buschman and van Beek (2003) proposed that offence related cognitive distortions are part of a larger underlying belief system. However, Buschman et al., (2003) suggested that the underlying belief system provides the basis for general interpersonal tendencies. Buschman argued that offenders' cognitive distortions are generated from a personality based cognitive network. This proposition suggests that trait based interpersonal tendencies, which are developed through the years, flavour the cognitive distortions of an offender. In other words, using a Beckian approach, offenders' core beliefs, and assumptions related to those core beliefs, mould their cognitive distortions about themselves, others and the world in general. For 
example, an offender grows up within a family environment where his behaviour is rejected and ridiculed. He develops core beliefs of inadequacy about himself and learns through a process of trial and error some basic assumptions. This offender would then use assumptions based around fear of rejection in his interpersonal encounters with all people and these beliefs would permeate his views of others and the world in general. An example of an assumption he has may be: "if I choose this child to have a sex with, then I'm less at risk of rejection".

Buschman and van Beek (2003) proposed that the large underlying belief system that is responsible for generating cognitive distortions, is pervasive and personality trait based. Some may argue that this proposition is contentious and has unhelpful implications for both child sex offenders and those who treat them. However, some of the thematically distinct cognitive distortions identified by Ward and Keenan (1999) possess similarities with the cognitions identified in DSM-IV-TR (APA, 2000) personality disorders. This in combination with the prevalence of personality disorders in the child sex offender population (described in the next section) warrants further investigation. The current study specifically focuses on how personality may influence distorted thinking in child sex offenders and how these thoughts filter into their offending beliefs. In the next section, the construct of personality and personality disorders are conceptualised and empirically reviewed in direct relation to child sex offenders.

\subsection{Personality Review}

The application of personality types and personality disorders to groups or individuals has met with controversy and ethical dilemmas. Some argue that the application of personality disorders or personality traits to individuals provides limited 
utility - and instead, is viewed as a channel for applying unhelpful, judgemental and pejorative labels (Mulder, 1997). Moreover, the stigma of being labelled with a personality disorder may hinder the therapeutic process. While there is merit in this argument, another point of view is offered. Individuals who exist within a psychological web of pervasive, inflexible and unhelpful cognitive, emotional, behavioural and interpersonal strategies can experience themselves, or cause others considerable disability and distress. What is also important to point out is personality disorder-related clinical presentations and sequalae place pressure on the mental health, forensic and correctional services.

Research has identified that individuals suffering from a personality disorder are at greater risk of developing other forms of psychopathology, e.g. somatisation disorder, mood disorders, anxiety disorders, phobias, alcohol and substance abuse, and eating disorders (DSM-IV-TR, APA, 2000). Mulder et al., (1994) found that 50\% of their New Zealand psychiatric client sample who initially presented with major depression, also suffered from a personality disorder; most commonly borderline, avoidant and paranoid personality disorders. Millon, Grossman, Millon, Meagher and Ramnath (2004, p. 8) illustrated the personality structure eloquently when they described personality as the psychological equivalent of the body's immune system. This parallel identified personality as having 'immune defences' which is made up of “coping skills and adaptive flexibilities". These defences then determine our susceptibility, or effectiveness in coping with, the psychosocial environment. Therefore, identification and management/treatment of personality disorder symptoms and their sequelae may provide beneficial preventative measures needed to manage the daily psycho-social environment. 
The objectives of the current personality review are to provide the reader with a definition of personality along with the difficulties of its complex nature and measurement. Two relevant theoretical conceptualisations of personality and personality disorders are offered; they include a brief outline of Millon's $(1969,1981$, 1990) Evolutionary Theory of Personality and Beck's (1965) Cognitive Theory of Personality. A description is provided on how personality is theoretically linked to child sex offending behaviour. Finally, a review of the relevant empirical personality literature is offered, as it relates to child sex offenders.

\subsection{Definition and Conceptualisation}

There are numerous definitions and conceptualisations of personality that have spawned a considerable body of research and debate. As a result, there is no consensus on a single universal definition of personality (Pervin, 1989). The difficulty in capturing a universal definition highlights the complexity of personality as a construct. Some of the prominent modern theoretical approaches to defining and conceptualising personality include: Psychoanalytic, Interpersonal, Phenomenological Person-Centred, Cattellian Trait Theory, Behavioural Theory, Social Cognitive Theory, Cognitive Information-Processing Theory, Cognitive Theory and Evolutionary Theory. Due to the many conceptualisations of personality available, a structured approach is needed to select a conceptualisation that provides the best fit for the current research.

For the purposes of the current study, the conceptualisation of personality needs to evolve from both theory and research and have a corresponding empirically developed, reliable measure. The measure of personality also needs to be applicable to a clinical-corrections population. Theodore Millon's conceptualisation of personality using an evolutionary framework and the corresponding Multi-Axial Clinical Inventory- 
III (1994) has been identified to meet these criteria. In addition, Millon's Evolutionary Model of Personality is used in the current research for its capacity to explore the nature and structure of personality on an adaptive and maladaptive level. Millon (1981, p. 8), defines personality as: "A complex pattern of deeply embedded psychological characteristics that are largely unconscious, cannot be eradicated easily and express themselves automatically in almost every facet of functioning." Millon also argues that personality also provides the foundation for an individual's "distinctive pattern of perceiving, feeling, thinking and coping”. This conceptualisation and definition is used to understand what personality is. The following theoretical conceptualisations will address how personality develops.

\subsection{Millon's Evolutionary Model of Personality and Personality Disorders}

In what was eventually labelled a Bio-Psycho-Social Model, Millon (1981; 1996) sought to explain the development of personality and its relationship to the DSMIV-TR (APA, 2000) personality disorders. This was achieved using a set of theory driven principles anchored in Evolutionary Theory. Millon's model offered an explanation of personality style and structure using polarities related to the adaptive, existence and replication evolutionary principles. By doing so, Millon developed a classification system that identified disordered personalities that are deficient, imbalanced or conflicted (refer to Table 1 for Millon's personality disorder classificatory schedule). The deficient are exactly that, completely devoid of specific evolutionary qualities. The interpersonally-imbalanced have a tendency to orient to one polar extreme or another. While the intrapsychically-conflicted battle with sometimes simultaneous tendencies toward opposing ends of the polarities. For example, the 
'passive-aggressive' alternates between conforming to others expectations while simultaneously behaving in a way congruent to their own gains.

Table 1. Millon's personality disorder classification matrix

\begin{tabular}{|c|c|c|c|c|c|}
\hline & \multicolumn{2}{|c|}{ Existential Aim } & \multicolumn{3}{|c|}{ Replication Strategy } \\
\hline & \multicolumn{2}{|c|}{$\begin{array}{l}\text { Life Enhancement vs. Life } \\
\text { Preservation }\end{array}$} & \multicolumn{3}{|c|}{ Propagation vs. Nurturance } \\
\hline Polarity & \multicolumn{2}{|c|}{ Pleasure vs. Pain } & \multicolumn{3}{|c|}{ Self vs. Other } \\
\hline \multirow[t]{2}{*}{$\begin{array}{l}\text { Deficiency, } \\
\text { Imbalance or } \\
\text { Conflict }\end{array}$} & $\begin{array}{c}\text { Pleasure (low) } \\
\text { Pain (low or } \\
\text { high) }\end{array}$ & $\begin{array}{l}\text { Pleasure-Pain } \\
\text { Reversal }\end{array}$ & $\begin{array}{l}\text { Self (low) } \\
\text { Other (high) }\end{array}$ & $\begin{array}{l}\text { Self (high) } \\
\text { Other (low) }\end{array}$ & $\begin{array}{l}\text { Self-Other } \\
\text { Reversal }\end{array}$ \\
\hline & \multicolumn{2}{|c|}{ Personality Disorder } & \multicolumn{3}{|c|}{ Personality Disorder } \\
\hline $\begin{array}{c}\text { Passive: } \\
\text { Accommodation }\end{array}$ & $\begin{array}{c}\text { Schizoid } \\
\text { Melancholic }\end{array}$ & Masochistic & Dependent & Narcissistic & Compulsive \\
\hline $\begin{array}{c}\text { Active: } \\
\text { Modification }\end{array}$ & Avoidant & Sadistic & $\begin{array}{l}\text { Histrionic } \\
\text { Hypomanic }\end{array}$ & Antisocial & $\begin{array}{l}\text { Passive- } \\
\text { Aggressive }\end{array}$ \\
\hline $\begin{array}{l}\text { Structural } \\
\text { Pathology }\end{array}$ & Schizotypal & $\begin{array}{l}\text { Borderline } \\
\text { Paranoid }\end{array}$ & Borderline & Paranoid & $\begin{array}{l}\text { Borderline } \\
\text { Paranoid }\end{array}$ \\
\hline
\end{tabular}

Millon's first principle, existence is also referred to as 'existential aims' (Millon, 1981; Millon \& Davis, 1996). Existence is continual processing and incorporating of information relating to life-enhancement and life-preservation. Life-enhancement motivates behaviour that enhances the likelihood of survival and improving the quality of life. Life-preservation orients the person to avoid actions or environments that lessen the likelihood of improving quality of life, or jeopardise existence itself. Existence provides the platform for Millon's ‘pleasure-pain' polarity. The 'pleasure-pain’ polarity provides a dimension on which one balances these primary existential aims. The schizoid personality disorder provides an example of a pleasure deficient personality structure whereby an individual with this personality disorder lacks the capability to experience or to enact pleasure and is generally indifferent to social interaction. Also appearing on this pole is the masochistic personality disorder where the existential aims 
of pleasure and pain are conflicted. For example, an individual with a masochistic personality disorder is reluctant to experience pleasurable activities and instead encourages others to exploit them, thereby experiencing pain.

Adaptation relates to what Millon refers to as 'homeostatic processes', or seeking balance and stability which is used to maintain existence (Millon, 1981; Millon \& Davis, 1996). This is achieved via the transference and receiving of information with the environment, in other words, interaction with the environment. Its corresponding dimension is the 'active-passive' pole. An active orientation is the disposition to modify or intervene in one's environment. A passive orientation is a disposition to accommodate to one's environment. These modes of adaptation follow on from the first phase of existence in that the adaptation mechanisms drive survival behaviour. The second phase, adaptation, provides the platform for the 'active-passive' polarity. For example an individual with a masochistic personality disorder are passive in allowing others to exploit them in order to reach their homeostasis level of discomfort. This is in contrast to an individual with a sadistic personality disorder who not only has a conflict in their 'pleasure-pain' polarity but also takes an active role in seeking to inflict pain in others using hostility and cruelty.

The third principle, replication, relates to the ultimate purpose of one's existence and relates to Millon's $(1981 ; 1996)$ 'self-other' polarity. Replication strategies were developed to ensure the on-going existence and survival of the species. These strategies are the self-propagating (the self pole) and nurturing tendencies (the other pole) that foster replication. 'The self' replication strategy maximises the potential to propagate and Millon (retrieved 2008) conceptualises the psychological style as "egotistic, insensitive, inconsiderate, and socially uncaring". The narcissistic personality disorder 
is an example of a personality disorder on 'the other' end of the 'self-other' polarity. An individual with a narcissistic personality disorder holds self-important indifference to the rights of others and is preoccupied with grandiosity and success. 'The other' replication strategy maximises the potential to propagate by protecting and sustaining offspring. Millon (retrieved 2008) suggests this behaviour is linked to actions that are "socially affiliative, intimate, caring, and solicitous". An individual with a dependent personality disorder leans to the other end of the pole by almost exclusively acting in a way that elicits the nurturance of others.

Millon identifies three additional personalities that he claims to be structurally deficient and deteriorated to an advanced stage of pathology. This separate 'severe' category includes schizotypal, borderline, and paranoid personality disorders. These personalities represent an insidious and slow deterioration of the personality structure. The criteria that differentiates these three personalities from the other personality structures include marked deficits in social competence, personality organisation, frequent psychotic episodes and a lack of effective coping strategies to deal with the strains of everyday life.

\subsection{Beck's Cognitive Theory of Personality and Personality Disorders}

Pretzer and Beck (1996, p. 44) claim that individuals are continuously "perceiving, recalling, interpreting and storing" information from within the environment. During the years of child development, our experiences shape how we perceive and interpret information in our environment. This provides the foundation for our basic beliefs and assumptions about ourselves, others and the world in general. These basic beliefs and assumptions then determine what information is attended to and how it is perceived and interpreted. These perceptions and interpretations shape our 
behavioural response to the information, which Beck et al., call 'strategies' (refer to Table 2 for cognitive profiles of each personality disorder and corresponding strategies). Key assumptions underlying the development of personality disorders include genetic predispositions and its interaction with negative or traumatic experiences (Beck, Freeman \& Davis, 2004).

As earlier mentioned, Beck (1963) originally developed the information processing model to explain and treat depression. This is commonly known as Beck's cognitive theory of depression (1963) which was previously outlined in the cognitive distortion review. Briefly, in his theory, Beck proposed that depression develops as a result of negative schemas (or beliefs) relating to 'the self', 'others' and 'the world in general', also known as the 'Beck Triad'. These negative schemas are generated as a result of developmental adversity and are deeply entrenched. Following a trigger or stressor of some description, these negative schemas are 'activated' and orient individuals to negative stimuli - resulting in a depressive episode. A negative schema in a depressed individual may be "I always mess up". According to Beck, this schema would orient the individual to notice information that confirms their schema. This selective attention also means that individuals typically don't attend to information that disconfirms their schema. In addition, depressed individuals also process neutral and ambiguous information as negative. However, depressed individuals' beliefs are activated during a bout of depression unlike individuals with a personality disorder who operate with these beliefs on a daily basis.

Similar to Millon (1981; 1996), Beck, Freeman and Davis (2004) propose that underlying the development of personality are evolutionary generated strategies. These strategies facilitate survival and reproduction. Beck et al., suggested that disorders such 
as depression, anxiety and personality disorders are manifestations of exaggerated strategies. At the core of this exaggeration is how individuals process affective and cognitive information, that is, emotions and thoughts. For example, much like Millon's approach, Beck, Freeman and Davis (2004) propose that a certain level of dependency is adaptive and functions to facilitate survival. However, in the case of dependent personality disorder, dependency is exaggerated to the point of dysfunction and distress. In this case, the need for dependency is driven by cognitions such as 'I can't survive without others taking care of me" and "if my partner left me, I'd fall apart" (2004, p. 276). These dichotomous and exaggerated beliefs result in high emotion and clinging behaviour. 
Table 2. Beck's cognitive profiles for the personality disorders

\begin{tabular}{|c|c|c|c|c|c|}
\hline $\begin{array}{l}\text { Personality } \\
\text { Disorder }\end{array}$ & Self-view & Core Beliefs & Assumptions & View of Others & Strategy \\
\hline Avoidant & $\begin{array}{l}\text { Socially inept \& } \\
\text { incompetent. Vulnerable to } \\
\text { rejection. }\end{array}$ & $\begin{array}{l}\text { I am... no good, worthless, } \\
\text { unlovable. I can't tolerate } \\
\text { unpleasant feelings. }\end{array}$ & $\begin{array}{l}\text { If people get close to me, } \\
\text { they'll find out I'm a fraud } \\
\text { and reject me. }\end{array}$ & $\begin{array}{l}\text { Critical, demeaning \& } \\
\text { superior }\end{array}$ & $\begin{array}{l}\text { Avoidance of evaluative } \\
\text { situations \& unpleasant } \\
\text { thoughts/feelings. }\end{array}$ \\
\hline Dependent & $\begin{array}{l}\text { Needy, weak, helpless \& ill } \\
\text { equipped. }\end{array}$ & $\begin{array}{l}\text { I am helpless \& all alone. I } \\
\text { won't survive without } \\
\text { someone to support me. }\end{array}$ & $\begin{array}{l}\text { I can function only if I } \\
\text { have access to someone } \\
\text { competent. }\end{array}$ & $\begin{array}{l}\text { Caretakers, competent \& } \\
\text { idealised. }\end{array}$ & $\begin{array}{l}\text { Subordinate self, placate } \\
\text { others \& acquiesce. }\end{array}$ \\
\hline $\begin{array}{l}\text { Passive- } \\
\text { Aggressive }\end{array}$ & $\begin{array}{l}\text { Self-sufficient } \& \text { sensitive } \\
\text { of encroachment by others. }\end{array}$ & $\begin{array}{l}\text { Being controlled is } \\
\text { intolerable - especially those } \\
\text { in authority. }\end{array}$ & $\begin{array}{l}\text { If I follow the rules, I'll } \\
\text { lose my freedom of action. }\end{array}$ & $\begin{array}{l}\text { Conflict between: } \\
\text { intrusive/ controlling \& } \\
\text { approving. }\end{array}$ & $\begin{array}{l}\text { Fortify autonomy by } \\
\text { devious opposition to } \\
\text { authority. }\end{array}$ \\
\hline Paranoid & $\begin{array}{l}\text { Righteous \& vulnerable to } \\
\text { mistreatment by others. }\end{array}$ & $\begin{array}{l}\text { I am... vulnerable to other } \\
\text { people. People are not to be } \\
\text { trusted. }\end{array}$ & $\begin{array}{l}\text { If I'm not careful, people } \\
\text { will abuse me and take } \\
\text { advantage. }\end{array}$ & $\begin{array}{l}\text { Inherently devious, } \\
\text { deceptive, untrustworthy } \\
\& \text { malevolent. }\end{array}$ & $\begin{array}{l}\text { Hypervigilance - } \\
\text { continual search for cues } \\
\text { of ill intent. }\end{array}$ \\
\hline Narcissistic & Special \& unique. & $\begin{array}{l}\text { I am superior and this should } \\
\text { be acknowledged. }\end{array}$ & $\begin{array}{l}\text { If others don't recognise } \\
\text { my special status, they } \\
\text { should be punished. }\end{array}$ & Potential admirers. & $\begin{array}{l}\text { Seek activities that } \\
\text { reinforce their superior } \\
\text { status. }\end{array}$ \\
\hline Histrionic & $\begin{array}{l}\text { Glamorous, impressive \& } \\
\text { deserving attention. }\end{array}$ & $\begin{array}{l}\text { I am... unattractive. I need } \\
\text { others to admire me to make } \\
\text { me feel happy. }\end{array}$ & $\begin{array}{l}\text { If I entertain or impress } \\
\text { people, then I am } \\
\text { worthwhile. }\end{array}$ & $\begin{array}{l}\text { Providers of attention, } \\
\text { approval \& appreciation. } \\
\text { Seducible. }\end{array}$ & $\begin{array}{l}\text { Dramatics \& } \\
\text { demonstrativeness. }\end{array}$ \\
\hline $\begin{array}{l}\text { Obsessive- } \\
\text { Compulsive }\end{array}$ & $\begin{array}{l}\text { Responsible for self and } \\
\text { others. }\end{array}$ & $\begin{array}{l}\text { I could be overwhelmed. } \\
\text { I am... disorganised. } \\
\text { I cannot fail. }\end{array}$ & $\begin{array}{l}\text { If I fail this, I am a failure } \\
\text { as a person. }\end{array}$ & $\begin{array}{l}\text { Casual, irresponsible, self- } \\
\text { indulgent or incompetent. }\end{array}$ & $\begin{array}{l}\text { Govern self \& others with } \\
\text { systems, rules standards \& } \\
\text { "shoulds" }\end{array}$ \\
\hline Antisocial & $\begin{array}{l}\text { A 'loner', autonomous \& } \\
\text { strong. }\end{array}$ & $\begin{array}{l}\text { I need to look out for myself. } \\
\text { I need to be the aggressor or } \\
\text { I will be the victim. }\end{array}$ & $\begin{array}{l}\text { If I don't push others } \\
\text { around, I will never get } \\
\text { what I deserve. }\end{array}$ & $\begin{array}{l}\text { Exploitative (dog eat dog) } \\
\text { Deserving by being weak, } \\
\text { vulnerable. }\end{array}$ & $\begin{array}{l}\text { Openly attack, manipulate } \\
\& \text { exploit. }\end{array}$ \\
\hline Schizoid & $\begin{array}{l}\text { Self-sufficient \& } \\
\text { autonomous. }\end{array}$ & $\begin{array}{l}\text { I can do things better if I'm } \\
\text { alone. }\end{array}$ & $\begin{array}{l}\text { I can't be happy unless I } \\
\text { have complete mobility. }\end{array}$ & Intrusive \& controlling. & Isolation \& distance. \\
\hline Borderline & $\begin{array}{l}\text { Vulnerable to abandonment, } \\
\text { unlovable, bad \& defective. }\end{array}$ & $\begin{array}{l}\text { I can't cope on my own. } \\
\text { I cannot bear tension \& } \\
\text { unpleasant feelings. }\end{array}$ & $\begin{array}{l}\text { If I rely on someone, I'll } \\
\text { be mistreated \& } \\
\text { abandoned. }\end{array}$ & $\begin{array}{l}\text { Idealised (perfect/loving) } \\
\text { and devalued (betraying/ } \\
\text { abandoning) }\end{array}$ & $\begin{array}{l}\text { relieve tension through } \\
\text { self-mutilation } \& \text { self- } \\
\text { destructive behaviour. }\end{array}$ \\
\hline
\end{tabular}

Beck, Freeman \& Davis (2004) 



\subsection{What Role Does Personality Play in Child Sex Offending Theory?}

Personality and/or interpersonal characteristics have been identified in etiological theories as important factors in explaining child sex offending behaviour (Hall \& Hirschman, 1991, 1992, 1996; W. L. Marshall \& Barbaree, 1990; Millon, 1981; Millon \& Davis, 1996). Hall and Hirschman (1991; 1992; 1996) identified four causal variables in their Quadripartite Model, which they proposed were motivational precursors of sexual aggression against women or children. These include: physiological sexual arousal, cognitive distortions, affective dyscontrol and developmentally related 'personality problems'. The four precursors were purported to, independently, or by interacting combinations, lead to sexually abusive behaviour. Men, who are sufficiently motivated on one or more of the four precursors, and exposed to triggering situational variables, will cross a threshold. This threshold would typically inhibit sexually aggressive behaviour in non-offending populations. Developmentally related personality problems were thought to result from adverse early experiences of familial abuse and ultimately become a vulnerability factor for sexual aggression. Hall and Hirschman (1996) describe the personality precursor as chronic with generalised propensity to violate rules, sexual aggression, violence and were deemed to have the poorest treatment prognosis.

Similar to Hall and Hirschman's Quadripartite Model, Marshall and Barbaree's (1990) Integrated Theory also emphasises offence related vulnerabilities that are generated by abusive developmental experiences. Exposure to precipitating situational factors is also a similar feature of the two theories. However, one of the many diverging factors between the two perspectives is reflected in Marshall and Barbaree's use of attachment as the construct explaining interpersonal difficulties. Marshall and 
Barbaree's Integrated Theory suggests that the abilities that are lacking as a result of an insecure attachment include: low self-esteem, poor coping style and inadequate interpersonal skills. These vulnerabilities (along with others, e.g. hormones, cultural norms, sexual attitudes) and situational factors help to explain sexual offending against women or children.

\subsection{Perceiving, Feeling, Thinking and Coping in Child Sex Offenders}

As previously noted, personality is a "distinctive pattern of perceiving, feeling, thinking and coping” (Millon, 1981, p. 8). Personality influences how we perceive, feel, think and cope on an individual and interpersonal level. We perceive others' intentions, behaviour, and state of mind; feel emotions as a result of interactions with others; we cope with the negative experiences in life; and think about ourselves, others and the world in general. These four capacities have been investigated in both the personality and child sex offender literature.

Personality is empirically linked with distinct coping strategies used during stressful situations (Bijttebier \& Vertommen, 1999; Lussier, Proulx, \& McKibben, 2001). Millon and Davis (1996) suggest that dysfunctional coping strategies can help distinguish adaptive, or 'normal' personality functioning from maladaptive personality functioning. While normal personality functioning uses flexibility of thought and problem focused coping, personality disorders are characterised by vicious cycles of inflexible, narrowed and maladaptive ranges of coping responses (Millon \& Davis, 1996). Moreover, Millon and Davis claim that an individual's range of coping skills and adaptive flexibilities determines his or her ability to master the demands of the environment. 
Sexual offending, whether it is against children or adults, has been proposed to function as a maladaptive coping strategy during times of negative emotional states and interpersonal conflict (Laws, 1989; Ward, Hudson, \& Marshall, 1995). Cortoni and Marshall (2001) investigated coping strategies in violent non-sexual offenders, adult sexual offenders and child sex offenders. They found that both adult sex offenders and child sex offenders used significantly more sexual coping strategies compared to violent non-sexual offenders. Further analysis showed that during adolescence, both adult and child sex offenders reported a significantly higher number of masturbation episodes per week than violent-non sexual offenders. Their results suggest that sex offenders may be more likely than other offenders to use sexual activities as a coping strategy during times of stress.

Ward (2000) proposed that child sex offenders have difficulties regulating their emotions. More specifically, they may have difficulty in identifying emotions, adjusting negative emotions to better cope with distress or may be unable to approach others for social support. Lussier et al., (2001) explored the link between personality and coping strategies in adult and child sex offenders using Millon's Clinical Multi-Axial Inventory (MCMI). Their cluster analyses revealed two MCMI profiles: dramatic and anxious. Those in the dramatic group showed higher personality trait scores on the histrionic, narcissistic, and compulsive scales. The anxious group revealed higher personality trait scores on the schizoid, avoidant, passive-aggressive, schizotypal and borderline scales. The anxious profile group had more offenders with deviant sexual preferences, as measured by phallometric means, and more paraphilia than the dramatic profile group. This indicates that the anxious group included more offenders with deviant sexual preferences or practices. 
There were some similarities between the groups. The results showed that both groups had difficulty in coping with negative emotional states, with inadequacy and anger being the most frequent negative emotional states. However, the anxious group reported significantly greater loneliness than the dramatic group. Differences in coping strategies according to personality group were evident. The dramatic personality group demonstrated a greater ability to cope with negative emotional states, interpersonal conflict and deviant sexual fantasies by using approach techniques (e.g., proactive problem solving). This is in contrast to the anxious personality group who utilised avoidant techniques (e.g., distraction). Lussier's research demonstrated that coping styles could be extracted from differing personality groups. This highlights how personality traits can influence both the dominant negative emotion felt by an individual and their coping style used during stress.

The literature identifies numerous and differing personality types and disorders within child sex offenders. It is important to note that used alone, Millon's MCMI personality scales do not allow for diagnosis. The personality scores are indicative of a personality type or personality traits, which at a certain level are clinically informing. Millon's MCMI personality scales are based on the DSM-IV-TR (APA, 2000) personality disorders. The MCMI provides supporting information for a diagnosis of personality disorder, in addition to other methods of assessment. In the forthcoming empirical review on personality in child sex offenders two terms are used. For those studies that utilise Millon's MCMI, the term personality trait scores is used to reflect a personality type consistent with the DSM-IV personality disorders. For those who use a diagnostic assessment methods that are directly related to the DSM-IV-TR (APA, 2000) criteria (e.g. SCID-II), the term personality disorder is used. 


\subsection{Empirical Review of Personality Disorders in Child Sex Offenders}

The measurement of personality within the offender population has been of interest since theorists proposed a link between personality and crime in the early to mid $20^{\text {th }}$ century. As a result researchers have explored personality traits using numerous measures among different offender groups. The data emerging from studies examining personality disorders in child sex offenders has shown that a high proportion of sampled offenders meet the DSM-IV-TR (APA, 2000) criteria for one or more personality disorders (Bogaerts, Daalder, Vanheule, Desmet, \& Leeuw, 2008; Bogaerts, Declercq, Vanheule, \& Palmans, 2005; Chantry \& Craig, 1994; Madsen, Parsons, \& Grubin, 2006). However, two issues have emerged from the literature: personality disorders identified within child sex offender samples vary (1) between offenders and; (2) between studies. This empirical review examines the results obtained in studies that measured personality traits consistent with the DSM-IV-TR personality disorders in child sex offender samples using Millon's MCMI-III or DSM-IV-TR (APA, 2000) criteria. This review begins with an overview of the prevalence of personality disorders in child sex offenders studied, followed by the distribution of personality disorders.

\subsubsection{Personality disorder prevalence in child sex offenders and 'normal'} populations.

Madsen et al., (2006) found high rates of incarcerated child sex offenders who met the DSM-IV-TR (APA, 2000) criteria for one or more personality disorders. Their results revealed that $48 \%$ of the sample met the criteria for at least one personality disorder. Eleven percent met the criteria for two personality disorders and $14 \%$ met the criteria for three or more. The results showed extensive overlap of personality types 
that reached a maladaptive level. This means that offenders were assessed to have more than one personality disorder, however, the types of personalities differed between individuals. Antisocial, avoidant, depressive, paranoid and obsessive-compulsive disorders were most frequent.

Bogaerts, Vanheule, Leeuw and Desmet (2006) also investigated personality disorder prevalence and attachment differences between 84 child sex offenders and a matched 'normal' control group of 80 non-offenders. Personality was assessed using the Assessment of the DSM-IV Personality Disorders (ADP-IV). Bogaerts et al., (2006) results showed that the child sex offender and the 'normal' control group varied on nine different personality types. The child sex offenders' personality trait scores were higher than the 'normal' control group on all of the personality scales. Bogaerts et al., (2006) also conducted a logistic regression to determine the unique variance that personality disorder type contributed to predict child sex offender group membership. The analysis showed that schizoid and antisocial personality trait scores significantly predicted child sex offender group membership. Additionally, insecure attachment styles as a result of increased paternal autonomy and decreased maternal care also achieve significance in predictive power of child sex offender group membership. Bogaerts et al.'s (2006) results support the existing research that identifies insecure attachment as a key feature in child sex offender offence related characteristics. Also relevant is the way increased personality trait scores contribute alongside insecure attachment in the prediction of child sex offender identification when compared to matched non-offender controls.

\subsubsection{Personality disorders in child sex offenders and other offender populations.}

Chantry and Craig (1994) conducted a study using the MCMI (Millon, 1983) to distinguish between child sex offenders', adult sex offenders' and violent (non-sexual) 
offenders' personalities. The MCMI data was collected from 603 offenders entering a forensic unit in the U.S.A. The data was analysed for statistical intra-group similarities and inter-group differences. The child sex offenders' mean MCMI personality trait scores were significantly higher than both adult sex offenders and violent (non-sexual) offenders on the passive-aggressive personality scale. The child sex offenders' mean personality trait scores were significantly higher on schizoid, dependent, and borderline compared to the violent (non-sexual) offender group. The child sex offender group profile analyses revealed dependant personality trait scores to be the highest. Chantry and Craig (1994, p. 433), described the clinical picture of the child sex offender group as showing "significant problems with dependency combined with psychic distress (anxiety and depression). They appear to be passive; submissive; insecure; docile; placating; and lacking in initiative, acquiescing to a strong adult authority figure for nurturance, affection, protection, and security".

Similar results were obtained by Ahlmeyer, Kleinsasser, Stoner and Retzlaff (2003) when they examined MCMI personality data in 472 child sex offenders, 233 adult victim sex offenders and 7,226 general population offenders within a U.S.A. penal institution. Their Odds Ratio analyses showed that specific personality scale scores could significantly predict child sex offender group membership when compared to the scores of adult sex offenders and general population offenders. The MCMI personality scales that predicted child sex offender group membership were schizoid, avoidant, depressive, dependent and self-defeating (masochistic) types. Ahlmeyer et al., (2003) conducted more conservative multivariate analyses using a logistic regression model with these five significant personality scales. The results identified dependent personality to be the single significant personality type most predictive of child sex 
offender group membership. The prominence of the dependant personality is consistent with Chantry and Craig's (1994) earlier data.

Fazel, Hope, O’Donnell and Jacoby (2002) examined personality traits within 101 convicted elderly child sex offenders and contrasted the results with those of 102 convicted elderly non-child sex offenders. The participants' ages ranged from 60 to 88 years with mean ages of 65.9 and 65.1 for the child sex offender group and non-child sex offender group, respectively. Fazel et al., (2002) assessed the participants' personality traits using the Structured Clinical Interview for DSM-IV Personality Disorders (SCID-II). Thirty-three percent of the elderly child sex offenders and 27\% of the elderly non-child sex offenders met the DSM-IV criteria for at least one personality disorder. Fazel et al., then compared DSM-IV-TR traits between offender groups. The results showed greater levels of schizoid and obsessive-compulsive traits and, to a lesser degree, avoidant traits in the child sex offender sample. Additionally, fewer antisocial traits were identified in the child sex offender sample compared with non-child sex offenders.

The empirical literature has identified important differences between subgroups of offenders. This confirms that child sex offenders do differ from other offenders at a personality level. The current study aims to examine personality differences within the child sex offender population. Therefore, the following section describes the intragroup personality differences within child sex offenders as a function of subcategories of child sex offenders.

\subsubsection{Personality disorders within the child sex offender population.}

Research exploring personality differences in child sex offenders has revealed significant differences among sub-groups of child sex offenders. Bogaerts, Declercq, 
Vanheule and Palmans (2005) investigated the predictive ability of interpersonal factors and personality disorders to discriminate between intra-familial and extra-familial child sex offenders. The sample consisted of 41 intra-familial, 43 extra-familial child sex offenders and 80 matched 'non-offender' control group participants, all whom were located in Belgium. Participants were assessed for personality disorders using the Assessment of DSM-IV personality disorders (ADP-IV). Logistic regression analysis showed that schizoid, narcissistic and avoidant personality disorders contributed significantly to the prediction of intra-familial offending where schizoid personality contributed the greatest. Antisocial, narcissistic and passive-aggressive personality disorders contributed significantly to the prediction of extra-familial child sex offender behaviour. In this group passive-aggressive personality disorder personality contributed the greatest. As hypothesised, Bogaerts et al., (2005) found clear personality disorder differences between intra and extra-familial child sex offenders, which opened the investigation for further distinctions as a function of personality.

Bogaerts, Daalder, Vanheule, Desmet \& Leeuw (2008) went on to investigated the prevalence of personality disorders within a sample of paedophile offenders (those who typically prefer pre-pubertal children as sexual partners) and non-paedophile offenders (those without a sexual preference for children). They also examined the impact personality disorders had on sexual offending. Thirty-six paedophile offenders and 34 non-paedophile offenders were administered the ADP-IV. The results indicated that the paedophile offenders had significantly higher incidences of borderline, histrionic, obsessive-compulsive and depressive personality disorders than nonpaedophile offenders. Further analysis revealed that obsessive-compulsive personality disorder accounted for $14 \%$ of the variance of child sex offending acts. Bogaerts et al., 
(2008) suggested obsessional tendencies and compulsive behaviours related to this personality disorder have an underlying influence on offending behaviour. Bogaerts et al.'s results also demonstrate that personality differences can be isolated according to child sex offender subgroup, i.e. paedophile and non-paedophile offenders. Their results are partially consistent with results obtained by Fazel et al., (2002).

\subsubsection{Distribution of personality disorders in New Zealand ethnicity groups.}

Wells (1989) conducted one of the earliest epidemiological studies related to the community prevalence rate of psychiatric disorders, including personality disorders. Wells (1989), found a $3 \%$ lifetime prevalence rate of antisocial disorder within the community sample. The picture is remarkably different within the prison system where one-month and lifetime prevalence rates of psychiatric disorders are significantly higher than community samples (Simpson, Brinded, Laidlaw, Fairley and Malcolm, 1999). A considerable proportion of personality disorder research in the New Zealand prison population relates to violent offenders and their antisocial traits (Brinded, Simpson, Laidlaw, Fairley, \& Malcolm, 2001; Simpson, Brinded, Fairley, Ladlaw, \& Malcolm, 2003; Simpson, Brinded, Laidlaw, Fairley, \& Malcolm, 1999). To date, there is limited empirical data relating to the distribution of personality disorders in child sex offenders within New Zealand, nor as a function of their ethnicity.

Simpson et al., (1999) conducted the National Study of Psychiatric Morbidity in New Zealand Prisons. Personality disorder traits were assessed using the Personality Disorder Questionnaire 4+ (PDQ4+) and a structured clinical interview. Within a sample of 1,248 male and female participants, $60 \%$ of prisoners presented with at least one personality disorder. Paranoid and antisocial personality disorders were the most prevalent within the sample with $50 \%$ of remanded and $40 \%$ of sentenced offenders 
reaching the diagnostic threshold for paranoid personality disorder. Forty-five percent and $41 \%$ of remanded and sentenced offenders, respectively, reached the diagnostic threshold for antisocial personality disorder. Personality disorders featuring in $25 \%$ or less of offenders included (in descending order): borderline, narcissistic, and histrionic personality disorders. Unfortunately neither offender group, index offence or ethnic identification were controlled for in this study.

Wilson (2004) used Millon's MCMI to investigate psychopathology and personality traits in a sample of New Zealand offenders serving custodial sentences. However, only $5 \%$ of participants within the sample were imprisoned for child sex offences. The relevance of Wilson's results for the current study is the distribution of personality types found within an incarcerated sample that were analysed according to ethnicity. The sample consisted of violent offenders, non-violent offenders, adult sex offenders, child sex offenders and miscellaneous offenders. Results showed $60 \%$ of offenders reached the clinical cut-off for prominent antisocial personality traits, $35 \%$ with paranoid personality traits, $27 \%$ with borderline personality traits and $16 \%$ with schizotypal personality traits.

Wilson's results from those identifying as Māori showed nominal difference in personality trait distribution. However, it was unclear from the study whether the comparison was between Māori and the entire sample, including (or excluding) Māori. The current study seeks to add to the literature by examining the distribution of personality trait scores in a New Zealand child sex offender sample and as a function of their ethnicity. As briefly outlined earlier, child sex offending is transcendent in nature - that is, offending transcends across 'social groups', including culture. Thus, social 
groups are an important variable to include in any investigation into child sex offender characteristics.

\subsubsection{Empirical Review Summary.}

Previous studies have demonstrated clear differences in personality disorders or personality traits scores across different offender populations and within child sex offender subtypes. This illustrates that child sex offenders can be distinguished from other groups of offenders and within subgroups of child sex offenders by using psychometric methods. Overall the results of the literature reviewed identified schizoidal and Cluster C (anxious and fearful; avoidant, dependant and obsessivecompulsive) personality disorders and personality trait scores to be the most prominent in sampled child sex offenders. However, there does appear to be considerable variability of personality traits and disorders both within and between studies. The central theoretical proposition of the current study posits that personality underlies the generation of cognitive distortions and guides the motivations of offending behaviour. The next section explains how this proposition is likely.

\subsection{The Relationship Between Personality Traits and Child Sex Offenders' Cognitive Distortions}

Ward and Keenan's (1999) Implicit Theories provides a useful framework in which to understand child sex offenders' perceptions of themselves and their victims. As mentioned, Buschman and van Beek (2003) proposed that cognitive distortions are a representation of offenders' underlying explanatory theories and general interpersonal tendencies. On a theoretical level, offence related cognitive distortions may be part of a global underlying personality structure that shares a thematically similar cognitive style. 
The variability of personality disorders within the child sex offender population may provide an understanding of their heterogeneous motivations and rationale for offending. The cognitive distortion review highlighted a number of thematically distinct cognitive distortions that are suggested to underlie child sex offenders' motivations for their offending. For example, the Dangerous World Implicit Theory may underlie an offender's motivation to punish their partner by offending against their partner's child. Using a Beckian 'schema' framework, the distorted (offence related) cognitions may emanate from the entrenched personality based cognitive structure. In other words, the cognitive distortion allowing the punishment against a partner by using her child may be generated by the paranoid personality disorder's retributive style of cognitions.

Another example is the Entitlement Implicit Theory where offenders' cognitive distortions are centred around a sense of entitlement to have their sexual needs met. The entitlement schema may be qualitatively similar to the narcissistic personality disorder cognitions that share an entitlement element. Does the narcissistic personality structure generate entitlement related cognitive distortions? Are the personality generated cognitions related in any way to offence related cognitive distortions? If so, what is the nature of this relationship? These are the central research questions for the current study. These questions will be explored to establish whether the cognitive distortions that Ward and Keenan propose are generated by Implicit Theories are linked to personality related cognitions.

\subsection{Framework and Hypotheses for the Present Study}

Due to the limited research that links personality types and with cognitive distortions, the hypotheses for the current study are exploratory in nature. However, 
tentative predictions are made based on the qualitatively similar cognitions found between the Implicit Theories and DSM-IV-TR (APA, 2000) personality disorder criteria. Firstly, the Dangerous World Implicit Theory is predicted to positively correlate with paranoid personality trait scores; the Entitlement Implicit Theory is predicted to positively correlate with narcissistic personality trait scores; the Uncontrollability Implicit Theory is predicted to positively correlate with antisocial personality trait scores. The relationship between both Nature of Harm and Children as Sexual Beings Implicit Theories and personality trait scores are purely exploratory.

In terms of distribution of personality types, it is hypothesised that a large percentage of child sex offenders will reach clinically significant personality trait scores; and that multiple personality scales will reach clinical significance within the individual offenders. The investigation of differences in personality traits scores between Māori and NZ-European/Pakeha child sex offenders is exploratory due to the paucity of research surrounding this question.

\subsection{Method}

\subsection{Participants}

Participants consisted of 30 male child sex offenders, of which 28 provided valid data. At the time of recruitment the participants were serving a custodial sentence for sexual offence/s against child victim/s under the age of 16. Participants were recruited from two Department of Corrections special treatment units in the North Island (Te Piriti) and the South Island (Kia Marama) of New Zealand. The 30 offenders who participated in the study were aged between 19 and 80 with the mean age being 44 years. A one-way ANOVA was conducted which identified the mean ages from both units differed at a significant level $(\underline{F}(1,26)=7.06, \underline{p}<.05)$. The 20 participants 
recruited from the Te Piriti Special Treatment Unit were significantly older ( $M=50.50$, $\mathrm{SD}=15.63)$ than the 10 participants recruited from Kia Marama special treatment unit $(\mathrm{M}=34.20, \mathrm{SD}=15.41)$.

Established in 1989, Kia Marama was New Zealand's first custodial specialist treatment programme for child sex offenders. The Te Piriti programme followed in 1994. Both the Te Piriti and Kia Marama Special Treatment Units provide highly structured, group based cognitive behavioural therapy. The Kia Marama treatment programme uses a predominantly Western psychological approach while the Te Piriti programme uses a fusion of Western and a Tikanga Māori approaches. Both of the highly structured programmes involve approximately 9 hours of group contact per week for a total duration of 33 weeks.

Eligibility to undertake treatment includes: admitting their offending, an absence of a mental illness that would interfere in treatment, volunteer for the treatment and be 20 years or older. Additionally, offenders must have a risk rating of medium-low or higher on the Automated Sexual Recidivism Scale (ASRS; Skelton et al., 2006) and STABLE-2007 (Hanson \& Harris, 2007). The ASRS is an actuarial risk assessment tool used by the New Zealand Department of Corrections to calculate the risk of reoffending by child sex offenders. The tool comprises static (or historical) variables including age of victim at time of offence, number of prior convictions for sexual offending, number of prior sentencing dates, any non-contact sexual offence convictions, prior non-sexual violent convictions and the gender of the victim. The ASRS risk categories range from low, medium-low, medium-high and high. The STABLE-2007 is a 13-item checklist used to assess changeable risk factors. Some of these include: social influences, cognitive problem solving, hostility towards women, 
emotional identification with children, sexual preoccupation, sex as coping, negative emotionality, loneliness and rejection, empathy and concern for others. In addition to the special treatment units' eligibility criteria, the current study required participants to possess a sufficient reading ability to complete the questionnaires without assistance.

\subsection{Instruments}

\subsubsection{The Implicit Theory Questionnaire (ITQ).}

The relevant cognitive distortions are measured with Ward and Keenan's (1999) Implicit Theories Questionnaire (ITQ; Goddard, unpublished). The ITQ comprises 204 items which make up the five Implicit Theory subscales (Children as Sexual Beings, Entitlement, Nature of Harm, Dangerous World, and Uncontrollability). Each item is presented as a statement to which a level of agreement or disagreement is required. The responses range from "strongly agree" to "strongly disagree" along with a "don't know" option. While relatively new in its development, the ITQ has yielded high internal reliability, with Cronbach's alphas ranging from .79 to .93 for all subscales. Test-retest reliability also yielded strong correlations for each subscale ranging between .84 and 1.00. The ITQ is used as a measure of attitudes and beliefs relating to the involvement of children in sexual activities (refer to Table 3 for example items). The ITQ takes approximately 45 minutes to one hour to complete. 
Table 3.

Implicit Theory Questionnaire (ITQ) subscales \& example items

\begin{tabular}{ll}
\hline Subscale & Example Items \\
\hline Children as Sexual Beings & $\begin{array}{l}\text { Children enjoy and want to engage in sexual activities with adults. } \\
\text { Children flaunt themselves in front of adults } \\
\text { Children are capable of seducing adults. }\end{array}$ \\
Entitlement & $\begin{array}{l}\text { One is entitled to get one's sexual needs met. } \\
\text { Children are ignorant about sex and need to be taught. } \\
\text { Children should be controlled. }\end{array}$ \\
Dangerous World & $\begin{array}{l}\text { Children are safer than adults. } \\
\text { Cou can't rely on anyone but yourself. }\end{array}$ \\
Children are more accepting and loving than adults. & $\begin{array}{l}\text { Some sexual assaults are not planned, they just happen. } \\
\text { Mncont things in life are down to luck. } \\
\text { Sex can happen by accident. }\end{array}$ \\
Nature of Harm & $\begin{array}{l}\text { Sexual acts between an adult and a child makes the relationship stronger } \\
\text { If the child loves you then having sex with them is ok. } \\
\text { People misinterpret acts as sexual. }\end{array}$ \\
\hline
\end{tabular}

\subsubsection{The Millon Clinical Multiaxial Inventory (MCMI-III).}

The measurement of personality trait scores is gathered using the Millon Clinical Multiaxial Inventory (MCMI-III). The MCMI-III is both a clinical and research tool and is routinely used by the New Zealand Department of Corrections as a measurement of personality traits within offender populations. The MCMI-III consists of 175 items that are consistent with the 14 Axis II personality disorders in the DSM-IV, seven subscales consistent with Axis I disorders and four validity scales. The MCMI-III scales have yielded moderate to high internal reliability, with Cronbach's alphas ranging from .66 to .89 for the personality scales. High test-retest reliability has also been established for each personality scale ranging between .85 and .93 . The MCMI-III is employed in its capacity to capture personality traits consistent with DSM-IV-TR personality disorders. 


\subsection{Procedure}

All offenders arriving at both Kia Marama and Te Piriti special treatment units were asked if they would like to participate in the current study. Offenders arrived at the units sporadically according to their sentence completion dates and unit space availability. This can be months prior to the commencement of the next treatment cycle. The collection of the Implicit Theory data coincided with the offenders' arrival at their respective treatment units in order to mitigate the likelihood of any treatment effects on cognitive distortions.

While seated in an intake waiting area, participants received an envelope containing an information sheet, consent form and the ITQ. On average, participants took 45 minutes to complete the ITQ, during which time the participants were alone. Upon completion of the questionnaire, participants' were instructed to place their ITQ into an envelope. Participants' sealed envelope was subsequently allocated a unique identification number, thereby maximising anonymity of participants and ensuring the subsequent link to their MCMI-III data. Psychometric testing is conducted with offenders at both units immediately prior to the commencement of their treatment. Included in Corrections psychometric battery is the MCMI-III. Offenders were provided with a quiet area to complete the inventory. The average time to complete the MCMI-III was approximately 25-30 minutes. Depending upon arrival date onto the unit, the gap between ITQ completion and MCMI-III completion varied.

\subsection{Results}

An alpha level of 5\% was used for all statistical analyses in this study. Means and standard deviations for personality trait scores and Implicit Theory endorsement are located in Tables 7 and 9, respectively. Participants' data was removed if they 
responded to less than two thirds of the ITQ items. As a result, two participants' data were removed from the ITQ dataset leaving a functional sample of 28. These two participants also provided invalid MCMI-III data due to disclosure scores below 34 .

\subsection{ITQ Reliability Analysis}

Internal reliability analyses were conducted to assess the degree to which each Implicit Theory subscale items were measuring the same phenomena. Five Cronbach's alpha scores were obtained showing high internal reliability for each Implicit Theory (refer to Table 4 for alpha coefficients for each subscale). Artificially high alpha coefficients can occur as a function of large item pools (Giles, 2002, p. 119). As a result, all subscales were reanalysed in smaller item pools of 12 items to ensure that the alpha coefficient was not artificially high. Giles (2002) recommends that inter-item correlation scores of greater than 0.3000 are considered to be highly reliable. Both Children as Sexual Beings and Nature of Harm subscales showed high internal consistency with few items scoring less than 0.3000 . However, a considerable proportion of items in Dangerous World, Entitlement and Uncontrollability subscales scored alpha coefficients lower than 0.3000 . This suggests that items in these subscales might be removed in order to refine and increase their reliability. This is not the focus of the current research and hence, all subscale items remained in the dataset so as to replicate earlier research using the ITQ. 
Table 4.

Cronbach's alpha coefficients for each Implicit Theory subscale

\begin{tabular}{lcc}
\hline Implicit Theory Subscales & Cronbach's alpha & Items per Subscale \\
\hline Children as Sexual Beings & 0.9576 & 45 \\
Nature of Harm & 0.9577 & 44 \\
Entitlement & 0.7875 & 38 \\
Dangerous World & 0.8331 & 40 \\
Uncontrollability & 0.9135 & 37 \\
\hline
\end{tabular}

All of the Implicit Theory subscales were significantly inter-correlated with the exception of the Dangerous World and Entitlement combination (refer to Table 5 for correlation results). However, of particular note is the level at which the Children as Sexual Beings and Nature of Harm subscales were significantly positively correlated. Participants who scored highly on Children as Sexual Beings subscale also scored highly on the Nature of Harm subscale. The analysis identified Children as Sexual Beings and Nature of Harm subscales to be almost perfectly correlated. Entitlement and Uncontrollability subscales also yielded a high correlation indicating that participants who scored highly on the Entitlement subscale, also scored highly on the Uncontrollability subscale. 
Table 5 .

Correlations between Implicit Theory subscales

\begin{tabular}{lcccc}
\hline & $\begin{array}{c}\text { Children as } \\
\text { Sexual Beings }\end{array}$ & $\begin{array}{c}\text { Dangerous } \\
\text { World }\end{array}$ & $\begin{array}{c}\text { Nature of } \\
\text { Harm }\end{array}$ & Uncontrollability \\
\hline Dangerous World & $.433^{*}$ & & \\
Nature of Harm & $.941^{* *}$ & $.413^{*}$ & & \\
Uncontrollability & $.635^{* *}$ & $.544^{* *}$ & $.506^{* *}$ & \\
Entitlement & $.628^{* *}$ & .284 & $.501^{* *}$ & $.722^{* *}$ \\
\hline ** Correlation is significant at the 0.01 level (2-tailed). & & \\
$*$ Correlation is significant at the 0.05 level (2-tailed). &
\end{tabular}

\subsection{MCMI-III Reliability Analyses}

The MCMI-III has four 'modifying indexes' that assist in identifying invalid or unreliable data. They include: the Validity Index, Disclosure Index, Desirability Index and the Debasement Index. All 30 participants produced valid responses according to the Validity Index. Two participants recorded a disclosure rating under the 34 cut-off, thereby making their inventory invalid (these participants were removed from the analyses), however, all remaining profiles were valid. Notable feature of the profiles include eleven participants who scored 75 or more on the desirability scale - suggesting their proclivity to "appear socially attractive, morally virtuous or emotionally well composed" (Millon, 1997, p. 118). Finally, two participants scored greater than 75 on the Debasement Index - suggesting an “inclination to depreciate or devalue one's self by presenting more with troublesome emotional and personal difficulties" than may be the case (Millon, 1997, p. 118). 


\subsection{Demographic Statistics}

Twenty-eight offenders provided valid data for the current study; twenty from Te Piriti special treatment unit and eight from Kia Marama special treatment unit. The percentage of NZ European/Pakeha participants was comparable to the percentage of Māori participants who took part in the study (refer to Table 6 for ethnicity breakdown according to treatment unit).

Table 6.

Ethnicity breakdown of participant sample

\begin{tabular}{lrccc}
\hline \multirow{2}{*}{ Ethnicity Identified } & \multicolumn{2}{c}{ S T Unit } & \multirow{2}{*}{ Frequency } & Percent \% \\
& Te Piriti & Kia Marama & & \\
\hline NZ European/Pakeha & 7 & 5 & 12 & 42.9 \\
Māori & 10 & 3 & 13 & 46.4 \\
Pacific Island & 1 & 0 & 1 & 3.6 \\
British & 1 & 1 & 2 & 7.1 \\
Total & 19 & 9 & 28 & 100.0 \\
\hline
\end{tabular}

\subsection{MCMI-III Distribution}

According to Millon (2003), the threshold for the clinical presence of personality traits is 75 while the threshold for clinically prominent personality traits is 85. Eighty-two percent (23) of the participants reached the threshold for the clinical presence of traits consistent with at least one DSM-IV-TR personality disorder. On average, each participant scored between 75 and 84 on two MCMI-III personality scales $(\mathrm{M}=2.04, \mathrm{SD}=1.73)$, ranging between zero and six, respectively. Of the 23 participants reaching the cut-off for the clinical presence of personality traits, over half (57\%) also had one or more personality scale that reached clinical prominence (i.e. 85 or greater). 
The masochistic personality scale received the greatest frequency count of scores reaching clinical presence, with nine of the twenty-eight participants scoring between 75 and 84 on this scale. The next most frequently observed personality scales reaching clinical presence were passive-aggressive, antisocial and depressive personality scales, each with seven participants scoring between 75 and 84 on these scales. The two greatest frequency counts of clinically prominent personality traits were passive-aggressive and antisocial with 4 participants each scoring 85 or greater on these personality scales (refer to Table 7 for MCMI-III descriptive statistics).

Table 7.

MCMI-III mean scores, standard deviations \& correlation coefficients with desirability $\underline{\text { scores }}$

\begin{tabular}{|c|c|c|c|c|c|c|c|}
\hline $\begin{array}{c}\text { Personality } \\
\text { Disorder }\end{array}$ & Minimum & Maximum & Mean & $\begin{array}{c}\text { Standard } \\
\text { Deviation }\end{array}$ & $\begin{array}{c}\text { Freq. of } \\
\text { Presence } \\
(75-84)\end{array}$ & $\begin{array}{c}\text { Freq. of } \\
\text { Prominence } \\
(85+)\end{array}$ & $\begin{array}{l}\text { Desirability } \\
\text { Correlation } \\
\text { Coefficient }\end{array}$ \\
\hline Paranoid & 1 & 88 & 59.29 & 19.64 & 1 & 2 & -.320 \\
\hline Borderline & 1 & 82 & 53.39 & 22.01 & 2 & 0 & $-.462 *$ \\
\hline Schizotypal & 0 & 82 & 53.36 & 25.58 & 4 & 0 & $-.549^{* *}$ \\
\hline Masochistic & 0 & 85 & 54.29 & 27.30 & 9 & 1 & $-.503^{* *}$ \\
\hline Negativistic & 1 & 90 & 57.93 & 28.45 & 7 & 3 & -.373 \\
\hline Compulsive & 21 & 83 & 48.50 & 14.54 & 1 & 0 & $.641^{* *}$ \\
\hline Sadistic & 5 & 89 & 52.54 & 22.53 & 2 & 1 & -.177 \\
\hline Antisocial & 16 & 95 & 66.11 & 20.18 & 7 & 4 & -.333 \\
\hline Narcissistic & 9 & 82 & 49.18 & 16.93 & 2 & 0 & $.713^{* *}$ \\
\hline Histrionic & 5 & 73 & 41.96 & 16.77 & 1 & 0 & $.930^{* *}$ \\
\hline Dependent & 30 & 92 & 62.11 & 17.89 & 5 & 2 & $-.531^{* *}$ \\
\hline Depressive & 0 & 110 & 65.43 & 23.94 & 7 & 4 & $-.635^{* *}$ \\
\hline Avoidant & 1 & 99 & 55.75 & 28.25 & 5 & 3 & $-.649^{* *}$ \\
\hline Schizoid & 1 & 106 & 56.71 & 22.82 & 5 & 1 & $-.652 * *$ \\
\hline Disclosure $^{a}$ & 14 & 98 & 62.97 & 19.86 & 2 & 5 & \\
\hline Desirability $^{\mathrm{b}}$ & 15 & 94 & 67.28 & 21.41 & 5 & 4 & \\
\hline Debasement $^{\mathrm{c}}$ & 0 & 85 & 50.10 & 23.90 & 1 & 1 & \\
\hline
\end{tabular}




\subsection{Social Desirability}

Thirty-nine percent of participants scored a desirability rating of over 75 , suggesting a tendency to "appear socially attractive, morally virtuous or emotionally well composed" (Millon, 1997, p. 118). (See Table 7 for correlation coefficients between personality scale scores and desirability scores.) Significant correlations were obtained between socially desirable responding and personality trait scores. Schizoid, borderline, schizotypal, masochistic, dependent, depressive and avoidant personality trait scores revealed a significant negative correlation with desirability scores. As participants' trait scores on the aforementioned personality scales increased, their desirability scores decreased. Offenders with high scores on compulsive, narcissistic and histrionic personalities revealed significant positive correlations with desirability scores.

\subsection{Ethnicity}

Mean paranoid personality trait scores differed significantly as a function of ethnicity identification $(\underline{F}(1,22)=7.35, \underline{p}<.05)$. Those participants who identified as Māori reported higher mean scores on the paranoid personality scale $(\underline{\mathrm{M}}=68.67, \underline{\mathrm{SD}}=$ 10.51) than those who identified as NZ-European/Pakeha $(\underline{\mathrm{M}}=49.33, \underline{\mathrm{SD}}=22.35)$. However, the mean score is still below the clinical interpretation threshold of 75 . Approaching significance was the difference in mean passive-aggressive personality trait scores between those identifying as Māori and NZ-European/Pakeha $(\underline{F}(1,22)=$ 3.61, $\mathrm{p}=.07)$. The passive-aggressive mean scores of Māori participants had a tendency to be higher $(\underline{\mathrm{M}}=68.08, \underline{\mathrm{SD}}=24.42)$ than NZ-European participants $(\underline{\mathrm{M}}=$ 48.42, $\underline{\mathrm{SD}}=26.29)$. Again, the mean score is still below the clinical interpretation threshold of 75. (Refer to Figure 1 for MCMI-III personality scale scores according to 
ethnicity.) There were no significant differences of mean endorsement levels of the five Implicit Theories according to ethnicity identification.

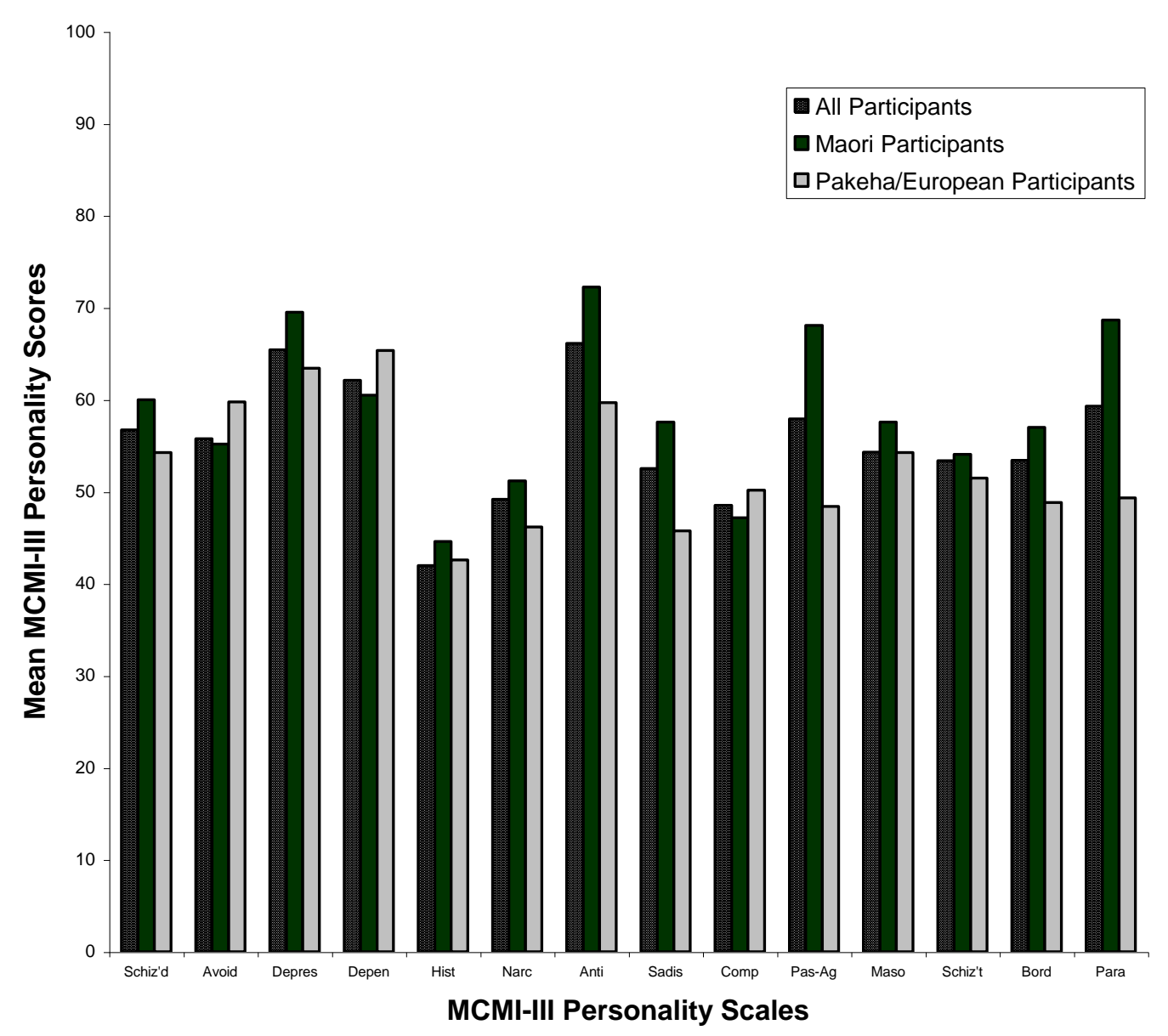

Figure 1.

Distribution of MCMI-III personality scale scores as a function of ethnicity

\subsection{Distribution of Implicit Theory Endorsement}

The Implicit Theory Questionnaire asked participants to evaluate statements; one=strongly disagree, $2=$ somewhat disagree $3=$ somewhat agree and 4=strongly agree . The highest mean score of Implicit Theory endorsement was the Dangerous World subscale (refer to Table 9 for descriptive figures and Figure 2 for visual explanation). 
Table 9.

Mean endorsement scores and standard deviations according to each Implicit Theory

\begin{tabular}{lcccc}
\hline \multicolumn{1}{c}{ Implicit Theory } & Minimum & Maximum & Mean & $\begin{array}{c}\text { Standard } \\
\text { Deviation }\end{array}$ \\
\hline Children as Sexual Beings & 1.00 & 3.33 & 1.47 & 0.50 \\
Dangerous World & 1.00 & 3.11 & 2.36 & 0.50 \\
Entitlement & 1.09 & 2.32 & 1.69 & 0.30 \\
Nature of Harm & 1.05 & 3.18 & 1.33 & 0.44 \\
Uncontrollability & 1.00 & 3.05 & 1.94 & 0.54 \\
\hline
\end{tabular}

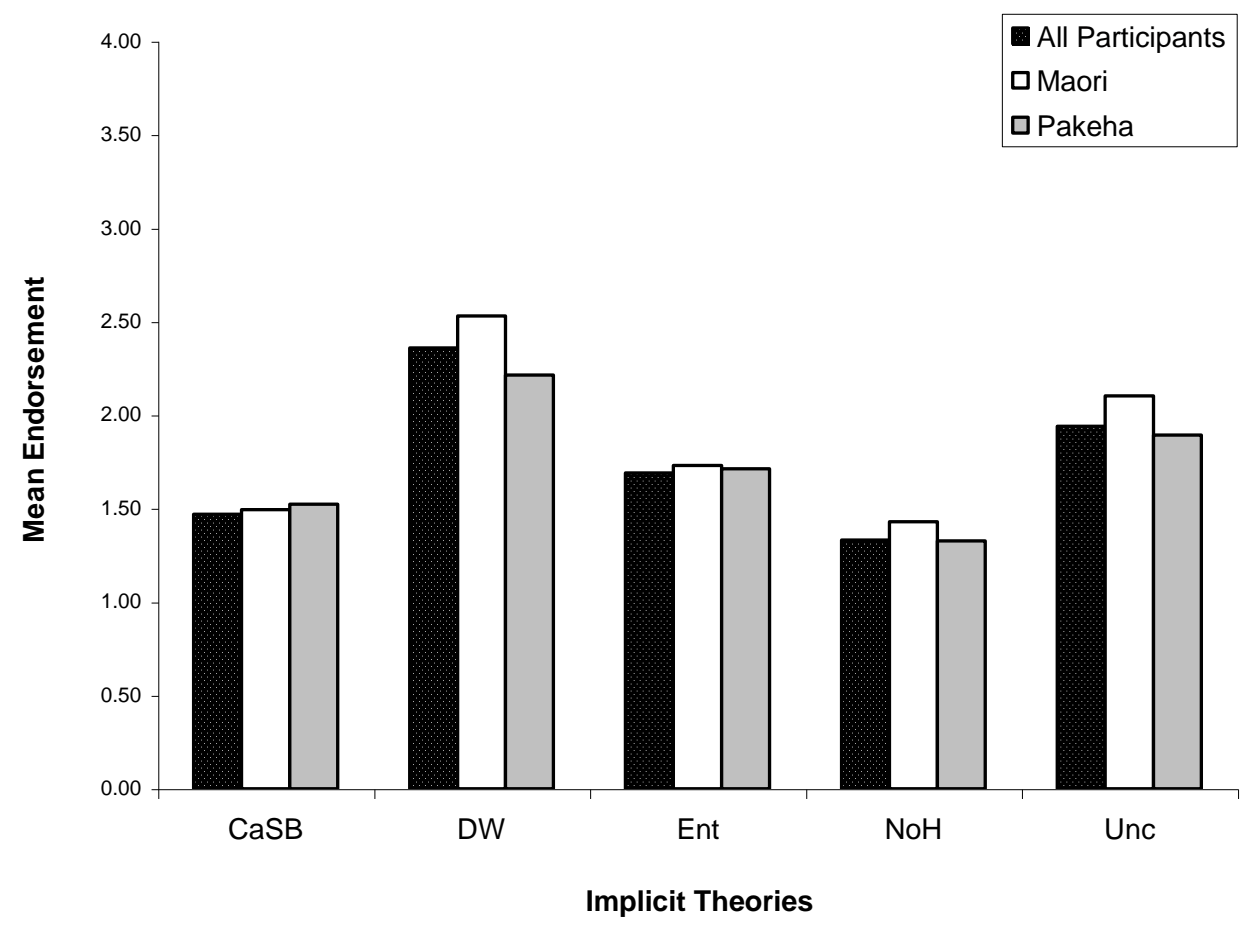

Figure 2.

Distribution of Implicit Theory endorsement as a function of ethnicity 


\subsection{Implicit Theory \& Personality Trait Score Correlations}

No significant relationships were revealed between endorsement scores of Children as Sexual Beings Implicit Theory and the MCMI-III personality scales. However, age of participants and endorsement scores of Children as Sexual beings approached significance $(\mathrm{r}=28,0.338, \mathrm{p}=.06)$. This result shows that as the age of the participants increased, the tendency was for endorsement of the Children as Sexual Beings Implicit Theory scores to also increase.

The results showed a significant positive correlation between Dangerous World Implicit Theory endorsement and dependent personality trait scores $(r=28,0.387$, $\mathrm{p}<0.05$ ). This indicates that as participants' dependent personality trait scores increase, so too did their endorsement of the Dangerous World Implicit Theory. Also reaching significance was the positive relationship between Dangerous World endorsement scores and depressive personality trait scores $(r=28,0.399, \mathrm{p}<0.05)$. This also shows that as participants' depressive personality trait scores increase, so too do their endorsement of the Dangerous World Implicit Theory. The positive trend between Dangerous World endorsement and paranoid personality trait scores approached significance $(r=28,0.366, p=0.06)$, suggesting a tendency for higher endorsement of the Dangerous World Implicit Theory and increased paranoid personality traits.

No significant relationships were revealed between the endorsement scores of Entitlement and Nature of Harm Implicit Theories and the MCMI-III personality scales. However, the results showed a significant positive correlation between Uncontrollability Implicit Theory endorsement and schizoid personality trait scores $(\mathrm{r}=28,0.404, \mathrm{p}<0.05)$. This indicates that as participants' endorsement of the Uncontrollability Implicit Theory increased, so too did their schizoid personality trait 
scores. Also reaching significance was the positive relationship between Uncontrollability endorsement scores and depressive personality trait scores $(r=28$, 0.499, $\mathrm{p}<0.01)$. This also shows that as the Uncontrollability endorsement increases, so too do participants' depressive personality trait scores.

\subsection{Discussion}

The hypotheses for the current study were exploratory in nature due to the paucity of research that examines links between personality traits and cognitive distortions using the MCMI-III (1994). However, tentative predictions were made based on similarities of cognitions between Ward and Keenan's (1999) Implicit Theories and cognitions identified in DSM-IV-TR (APA, 2000) personality disorders. It was proposed that the Entitlement Implicit Theory would be positively correlated with narcissistic personality traits; Dangerous World Implicit Theory positively correlated with paranoid personality traits; and Uncontrollability Implicit Theory would be positively correlated with antisocial personality traits. Nature of Harm and Children as Sexual Beings Implicit Theories were not predicted to correlate with any one personality subscale and instead the analyses were purely exploratory. The investigation of personality trait scores between Māori and NZ-European/Pakeha child sex offenders was also exploratory in nature.

The high degree of inter-correlation between the five Implicit Theories suggests that commonalities between the constructs are evident. Notably, Nature of Harm and Children as Sexual Beings were almost perfectly correlated. Shared features between the two Implicit Theories include the grey area between sexual contact with a child being beneficial and not harmful. Both share the belief that sexual contact is beneficial and is unlikely to cause harm. A point of difference between them however, shows that 
those who hold Children as Sexual Beings Implicit Theory believe that children have the capacity to understand, be informed, make decisions and outwardly seek sexual encounters. This is unlike the Nature of Harm Implicit Theory where children can be a passive party to the sexual contact, and in fact, completely unaware of it taking place. Further investigation and refinement of both the constructs and subscale measures may provide a more sensitive instrument with which to tease apart these Implicit Theories.

Across the five Implicit Theories, Dangerous World obtained the highest endorsement and Nature of Harm the lowest. However, overall, the participants' endorsement levels were low. This may be due to a number of possibilities; a) that the participants were providing socially desirable responding (Gudjonsson \& Sigurdsson, 2000; Nugent \& Kroner, 1996); b) the participants' ability to reflect on their offence related cognitions was limited due to the collection of data timed prior to treatment commencement (i.e. they haven't explicitly thought about their offending beliefs like they are requested to in-treatment; c) admission of their offence related cognitions was impeded by the correctional setting (Kaplan, 1985); and d) the low-medium risk offenders who participated in the study provided endorsement levels reflecting this lowmedium risk. As mentioned previously, child sex offenders typically disagree with cognitive distortions (Gannon \& Polaschek, 2005). The low level of Implicit Theory endorsement may actually be greater given the private and socially deviant nature of sexual connection with children. Despite the general disposition for child sex offenders to disagree with cognitive distortions, the current research has extracted a level of cognitive distortion endorsement that has provided useful data alongside personality trait scores. 
The results partially supported the tentative predictions relating personality traits with cognitive distortions generated by the five Implicit Theories. As offenders endorsement of the Dangerous World Implicit Theory increased, so too did their levels of dependent and depressive personality traits. The nature of this relationship suggests that there are qualitatively similar social-cognitions apparent in both the personality types and the Dangerous World Implicit Theory. Those who hold the Dangerous World Implicit Theory believe the world to be a hostile and malevolent environment filled with people who are prepared and willing to harm them. It is not too surprising to find a link between this view of the world and those with dependent personality traits. Those with dependent traits perceive themselves as weak, helpless and fragile to the point where they fear being alone to care for themselves. They also have childlike impressions of others and limited competencies in managing and resolving stressful situations. Those with dependent traits also entrust others to carryout the 'adult' functions and responsibilities in their lives, leaving underdeveloped abilities to function independently. This in turn sets them up for habitually seeking the support and nurturance of others to fill the vacancy left by their perceived ineptitude to function and care for themselves. Those with dependent traits may endorse the fearful strand of Ward and Keenan's (1999) Dangerous World Implicit Theory. That is, offenders endorse the belief that the world is a threatening place where adults are untrustworthy and rejecting while children are more dependable.

A further relationship was found whereby Dangerous World endorsement increased with depressive personality traits. Those with depressive personality traits are heavy-hearted, dispirited individuals with a sense of permanent hopelessness. Within their social environment they perceive themselves as defenceless with feelings of being 
vulnerable and assailable. Those with depressive personality traits will act in an endangered way and demand assurances of affection, steadfastness and protection. Some of these traits are not dissimilar to those of dependant personality traits. The results suggest that the depressive cognitive traits run parallel to the beliefs generated by the Dangerous World Implicit Theory. The nature of this relationship may relate to the negative pessimistic outlook on the self, others and the world in general. Depressive cognitive traits are flavoured with pessimism regarding all matters and permanently perceiving the worst with their fatalistic attitudes.

The relationship between paranoid traits and Dangerous World endorsement was tentatively predicted, however, the results only identified a trend approaching significance. Only three participants in the current study had scores showing the presence of paranoid traits or prominent traits. Given a larger sample size this may have reached significance. A relationship between these two constructs appears intuitive since the paranoid traits are primarily interpersonally suspicious in nature. Those with paranoid personality traits are vigilantly guarded in order to fend off imminent and expected malice or deception by others. Their interpersonal, or social-cognitions relating to others include suspicion, scepticism and mistrustfulness of others' motives. The difference between dependant/depressive traits and paranoid traits is that an individual with paranoid traits does not perceive themselves as defenceless or passive to others' malevolence. Some of the paranoid personality traits coincide with the first strand of Ward and Keenan's Dangerous World Implicit Theory. This strand suggests that the world is inherently hostile and an individual needs to assert their dominance and control over others to ensure their position is strengthened. 
The Uncontrollability Implicit Theory was the only other Implicit Theory to reveal relationships with personality traits. As offenders endorsement of the Uncontrollability Implicit Theory increased, so too did their levels of schizoid and depressive personality traits. Those who hold the Uncontrollability Implicit Theory believe the world is uncontrollable and one is powerless in managing or exerting influence over anything in their existence, including emotions, sexual urges or behaviours. Beliefs of this nature provide a lowered sense of responsibility and heightened sense of victimisation. The relationship with schizoid personality traits was not predicted. Moreover, the commonalities between constructs are not as clear-cut as the traits related to the Dangerous World Implicit Theory. Upon closer examination of the schizoid personality, the central traits relate to apathy, indifference and social isolation. However, Millon \& Davis (1996) propose there are four subtypes of schizoid personalities; affectless, remote, languid and depersonalised.

The first of Millon \& Davis' (1996) Schizoid subtypes, 'affectless', refers to the unresponsive, diminished emotions and generally uncaring nature of their demeanour. The 'remote' subtype captures the schizoidal traits relating to their inaccessibility, drifting lifestyle and solitary preferences. Millon and Davis' 'languid' subtype includes the distinct inertia and lethargy. Finally, the 'depersonalised' subtype suggests that the individual is dislocated from other individuals as well as the self, they perceive the self as disconnected from body and mind. The depersonalised schizoid personality provides a clearer explanation of the relationship between schizoid trait scores and the Uncontrollability Implicit Theory. The disconnect between the mind and body is a key feature between the two. Applying it to the Uncontrollability Implicit Theory, the sex 
offender believes the mind has no control over emotions or behaviour, especially sexual urges.

Depressive personality traits were also correlated with Uncontrollability Implicit Theory. Again, this relationship was not predicted and the nature of the relationship posed a challenge to investigate. Millon (1987), describes the cognitive style of an individual with depressive personality traits as "fatalistic". This may be the central cognitive trait that intersects the depressive traits with Uncontrollability Implicit Theory. A fatalistic attitude may foster a sense of disempowerment and a lack of influence over their life and environment. This might be the common cognitive trait linking the two. However speculative the connections may be between the personality traits and Implicit Theory generated cognitive distortions, the results provide relevant information in the context of any cognitive behavioural treatment programme.

The Entitlement Implicit Theory did not reveal any relationship with narcissistic personality traits. However, this may be due to a number of reasons. Two participants were removed from the dataset for only partially completing the ITQ. Both of these participants showed high narcissistic trait scores. The limited number of offenders within the sample may be a sampling bias where offenders with high narcissistic traits may not elect to take part in a) treatment or b) research conducted by a student.

Consistent with previous findings in the literature (Bogaerts et al., 2008; Bogaerts et al., 2005; Chantry \& Craig, 1994; Madsen et al., 2006), the majority of child sex offenders in the current sample showed evidence to support the clinical presence of at least one type of maladaptive personality type as measured by Millon's MCMI-III (1994). A considerable number of participants also showed evidence for more than one type. This suggests that as a group, the prevalence rate for the clinical presence and 
prominence of disordered personality traits is high. However, much like the mixture of personality types identified within the reviewed literature, masochistic, passiveaggressive, antisocial and depressive were most frequently observed within the sample. Of particular interest were the high levels and high frequency counts of traits consistent with masochistic and depressive personality disorders in the participants.

One third of the sample reported high levels of masochistic personality traits that includes: choosing peers who mistreat them, not being deserving of good things that happen, feeling sad after something good has happened, creating situations to be rejected, undeserving of pleasure and becoming confused and upset when people are kind to them. Those with masochistic traits tend to have beliefs that are self-debasing, being worthy of shame and deserving of punishment for not living up to the expectations of others. The internalisation of their offending and the nature of their current custodial environment may have contributed to any shameful and self-debasing self-images they may possess. To explore this further, one would need to conduct a pre and post-treatment personality inventory to assess for transient environmental or socially generated beliefs. In addition, the level of ostracization participants feel they have received before prison and whilst in prison may help tease apart their situationbased beliefs from their trait-based beliefs.

Depressive personality traits were also evident within a large proportion of the sample. The self-image of an individual with depressive traits is one of wretchedness, being valueless, reproachable and even contemptible. As a result of these core beliefs, their behaviours ensure self-denial of pleasure, self-punishment of which can include self-destructive acts. These traits are in some respects, qualitatively similar to the 
masochistic personality traits - in particular, the undeserving core beliefs and selfpunishing behaviours.

Despite the current sample holding high levels of traits consistent with all of Millon's personality types in the MCMI-III (1994), only a selection of them reached statistical significance when related to Implicit Theories. Majority of the personality types reaching significance with the Implicit Theories were identified in the literature as predicting child sex offender group membership. More specifically, Ahlmeyer et al.,'s (2003) results found schizoid, avoidant, depressive, dependent and self-defeating (masochistic) personality types predicted child sex offender group membership.

The ethnicity results showed Māori to have higher levels of paranoid personality traits compared to those who identified as NZ-European/Pakeha. A difference was revealed in paranoid personality traits and a trend towards Māori reporting higher passive-aggressive personality traits. The results demonstrated that Māori child sex offenders who elect to partake in treatment have greater levels of paranoid personality traits than NZ-European/Pakeha offenders. This would suggest that those assessing and treating Māori child sex offenders should be mindful of process issues stemming from their paranoid and primarily suspicious cognitive style.

So, what do these results mean for child sex offenders? A number of personality traits that were identified within the child sex offenders sampled, were related to their 'offence supportive beliefs' or cognitive distortions. This might suggests that on a cognitive level, child sex offenders with specific personality traits perceive the self, others and the world in general much like Ward and Keenan's (1999) Dangerous World and Uncontrollability Implicit Theories. This raises the question, are these cognitive distortions related to a larger and more pervasive personality based cognitive structure? 
This would suggest that the offence related explanatory theories that permit an individual to sexually offend against a child are in direct relation to their global social cognitions. These global social cognitions create a set of expectations, of which, are thematically linked to their offending beliefs. In other words, offenders' personality based beliefs and perceptions of themselves, others and the world in general, flavour their existence on every level - including their offending. Therefore, child sex offenders' cognitive distortions may be an offence related application of their underlying personality structure. For example, the child sex offender with dependent personality traits may be more likely to hold erroneous offending beliefs that are congruent with the sometimes childlike, dependant cognitions - "The world is dangerous and full of adult difficulties that I cannot deal with, children understand me though."

The heterogeneity of offenders' motivations to offend, together with their distorted cognitions relating to their offending may be reflected in the variability of personality types seen within the child sex offender literature. For example, those who are motivated by their perceived lack of control over their sexual urges may have more schizoidal traits than those who offend to seek nurturance from the safety of a child. Thus, the personality types observed may predict an element of their offending beliefs. The current study has demonstrated a clear relationship between Dangerous World and Uncontrollability Implicit Theories and personality traits. The underlying connection between the two lies in offenders' cognitive styles. Trait-based cognitions may be employed by offenders to generate and develop offending beliefs which flavour their motivation to offend. 
The results of the current study have clinical importance ranging from assessment to treatment within multiple settings including those in custody and in the community. Adequate treatment requires a thorough assessment and the targeting of maintaining factors for intervention. When using the CBT approach, these targeted areas are typically cognitive and behavioural. Similar to Ward and Keenan's (1999) approach, the results of the current study suggest that cognitive distortions may not be offence specific. Instead, they may be generated by offenders' wider and deeper entrenched views of themselves, others and the world in general. A treatment approach that combines the targeting of personality generated offence cognitions may need to be more intensive and elongated in order to adjust the inflexible cognitive style linked with personality. This may require an element of treatment to be drawn from the personality disorder treatment literature, e.g. Acceptance and Commitment Therapy, Dialectical Behavioural Therapy.

A number of methodological factors may have mitigated the likelihood of further significant results. If rectified, the data may have enhanced the scope, generalisability and reliability of the findings. Firstly, the treatment of child sex offenders is voluntary. The current study's sample included only those child sex offenders who elected to take part in treatment. This sampling limitation means that those offenders who did not elect to take part in treatment are not represented in the sample. Also not represented in the current sample are the child sex offenders whose offences evade detection, conviction and a custodial sentence. As a result, all implications and applications of the current results can only be generalised to child sex offenders who volunteer for treatment within a custodial environment. This limitation would be mitigated by sourcing additional groups of child sex offenders such as a group 
of offenders who did not elect to seek treatment and a non-custodial community sample. Personality traits and offence related cognitions may be qualitatively different in those who refuse treatment and those who are in the community being treated. This proposition warrants further investigation.

The Implicit Theory Questionnaire was used to gauge offenders' most dominant thematically distinct cognitive distortions. However, the Nature of Harm and Children as Sexual Beings subscales were noted to overlap considerably. Also, the internal reliability of some items within the Entitlement and Uncontrollability and Dangerous World were below the recommended range. Modification of items in the Nature of Harm and Children as Sexual Beings subscales may increase the sensitivity to distinguish between the two constructs. Further refinement of the Implicit Theory Questionnaire is required to ensure precision and reliability of any future data collection. Developing a truncated version may also be of assistance due to the length of time to complete the measure.

In summary, future research to advance the current study would include several possibilities. Firstly, it would be beneficial to increase the sample size and include additional participant groups, who a) did not volunteer for treatment; b) are in a community treatment sample; and c) non-offender controls. By enhancing the sample size there is more likelihood of obtaining statistical power to identify additional significant findings. The inclusion of different groups may increase the chance of identifying personality differences according to those who volunteer for treatment and those who do not. Also of value would be to ascertain the degree to which each group endorses the Implicit Theory cognitive distortions. 
Also of interest would be to assess the ITQ and personality trait scores of recidivist child sex offenders. Do those who have greater levels of reoffending also have greater endorsement of cognitive distortions and higher personality trait scores? Under the assumption that higher personality trait scores predict greater difficulties in coping, thinking, feeling and perceiving, does it also predict higher levels of maladaptive coping i.e. child sex offending. This may assist in determining the treatment efficacy in those with low personality trait scores versus high personality trait scores.

Overall, the current study has offered important findings to inform both the literature along with the assessment and treatment of child sex offenders. Thematically distinct offence related cognitive distortions have been identified to significantly correlate with personality types consistent with DSM-IV-TR personality disorders. Specifically, offenders' depressive and schizoidal personality traits were identified to converge with the cognitive distortions linked with Ward and Keenan's (1999) Uncontrollability Implicit Theory. Also, offenders' depressive and dependant personality traits converged with Ward and Keenan's Dangerous World cognitive distortions, with paranoid personality traits showing a trend to do so also. Additional useful findings identified Māori child sex offenders to possess higher levels of paranoid personality traits than NZ/European-Pakeha child sex offenders, with passiveaggressive personality traits showing a trend to be higher also. This result illustrates the need for the assessment and treatment process of child sex offenders to include the likelihood of differences in social cognitions according ethnic grouping.

The relationship of offenders' personality traits and cognitive distortions is suggested to converge at a social cognitive level where offenders' overall interpersonal 
tendencies flavour their cognitive distortions. These overall interpersonal tendencies are speculated to emanate from a personality based cognitive network. This would suggest that offenders' personality traits may provide a window into their offence related cognitions. Practical implications would then include assessing personality trait cognitions in relation to offenders' cognitive distortions to better understand their offence chain and challenge their overarching social cognitions. However, it is also important to mention that despite the current study's attempt to classify child sex offenders into homogenous groups according to personality and cognitions, it is critical that all offenders receive careful attention to understand their individual factors that lead to the initiation and maintenance of their offending. 


\section{References}

Abel, G. G., Becker, J. V., \& Cunningham-Rathner, J. (1984). Complications, consent, and cognitions in sex between children and adults. International Journal of Law and Psychiatry, 7(1), 89-103.

Abel, G. G., Becker, J. V., Mittelman, M., Cunningham-Rathner, J., Rouleau, J. L., \& Murphy, W. D. (1987). Self-reported sex crimes of nonincarcerated paraphiliacs. Journal of Interpersonal Violence, 2(1), 3-25.

Abel, G. G., \& Rouleau, J. L. (1990). The nature and extent of sexual assault. In W. L. Marshall, D. R. Laws \& H. E. Barbaree (Eds.), Handbook of Sexual Assault: Isues, Theories, Treatment of the Offender (pp. 9-21). New York: Plenum Press.

Ahlmeyer, S., Kleinsasser, D., Stoner, J., \& Retzlaff, P. (2003). Psychopathology of incarcerated sex offenders. Journal of Personality Disorders, 17(4), 306.

Barbaree, H. E., Marshall, W. L., \& McCormack, J. (1998). The development of deviant sexual behaviour among adolescents and its implications for prevention and treatment. Irish Journal of Psychology - Special Issue, 19, 1-31.

Beck, A. (1963). Thinking And Depression. Archives of General Psychiatry, 14(324$33)$.

Beck, A. T., Freeman, A., \& Davis, D. D. (2004). Cognitive therapy of personality disorders (2nd ed.). NY: Guilford Publications, Inc.

Bijttebier, P., \& Vertommen, H. (1999). Coping strategies in relation to personality disorders. Personality and Individual Differences, 26, 47-856.

Bogaerts, S., Daalder, A., Vanheule, S., Desmet, M., \& Leeuw, F. (2008). Personality disorders in a sample of paraphilic and nonparaphilic child molesters. International Journal of Offender Therapy and Comparative Criminology, 52(1), 21.

Bogaerts, S., Declercq, F., Vanheule, S., \& Palmans, V. (2005). Interpersonal factors and personality disorders as discriminators between intra-familial and extrafamilial child molesters. International Journal of Offender Therapy and Comparative Criminology, 49(1), 48-62.

Bogaerts, S., Vanheule, S., Leeuw, F., \& Desmet, M. (2006). Recalled parental bonding and personality disorders in a sample of exhibitionists: a comparative study. Journal of Forensic Psychiatry \& Psychology, 17(4), 445-458.

Brinded, P. M., Simpson, A. I. F., Laidlaw, T. M., Fairley, N., \& Malcolm, F. (2001). Prevalence of psychiatric disorders in New Zealand prisons: a national study. Australian and New Zealand Journal of Psychiatry, 35(2), 166-173.

Buschman, J., \& vanBeek, D. (2003). A clinical model for the treatment of personality disordered sexual offenders: an example of theory knitting. Sexual Abuse: A Journal of Research and Treatment, 15(3), 183-199.

Chantry, K., \& Craig, R. J. (1994). MCMI typologies of criminal sexual offenders. Sexual Addiction \& Compulsivity, 1(3), 215-226.

Choudhry, R. K. (1995). Cognitive distortions of incest and non-incest offenders. Unpublished M.A., University of Toronto (Canada), Canada.

Cortoni, F. A., \& Marshall, W. L. (2001). Sex as a coping strategy and its relationship to juvenile sexual history and intimacy in sexual offenders. Sexual Abuse: A Journal of Research and Treatment, 13, 27-43. 
Craissati, J., McClurg, G., \& Browne, K. (2002). Characteristics of perpetrators of child sexual abuse who have been sexually victimized as children. Sexual Abuse: A Journal of Research and Treatment, 14(3), 225-239.

English, K., Jones, L., Patrick, D., \& Pasini-Hill. . (2003). Sexual offender containment: Use of the postconviction polygraph. Annals of the New York Academy of Sciences, 989, 411-427.

Fazel, S., Hope, T., O'Donnell, I., \& Jacoby, R. (2002). Psychiatric, demographic and personality characteristics of elderly sex offenders. Psychological Medicine, 32, 219-226.

Feelgood, S., \& Hoyer, J. (2008). Child molester or paedophile? Sociolegal versus psychopathological classification of sexual offenders against children. Journal of Sexual Aggression, 14(1), 33-43.

Fernandez, Y. M., Anderson, D., \& Marshall, W. L. (1999). The relationship among empathy, cognitive distortions and self-esteem in sexual offenders. In B. K. Schwartz (Ed.), The sex offender: Theoretical advances, treating special populations \& legal developments (pp. 1-12). Kingston: Civic Research Institute.

Festinger, L. (1957). A Theory of Cognitive Dissonance. Standford CA: Stanford University Press.

Gannon, T. A., \& Polaschek, D. L. L. (2005). Do child molesters deliberately fake good on cognitive distortion questionnaires? An information processing-based investigation. Sexual Abuse: A Journal of Research and Treatment, 17(2), 183200.

Gannon, T. A., Ward, T., \& Polaschek, D. L. L. (2004). Child Sexual Offenders. In Violence in society: New Zealand Perspectives. Christchurch: Te Awatea Press.

Gudjonsson, G., \& Sigurdsson, J. F. (2000). Differences and similarities between violent offenders and sex offenders. Child Abuse \& Neglect, 24, 363-372.

Hall, G. C. N., \& Hirschman, R. (1991). Towards a theory of sexual aggression: A quadripartite model. Journal of Consulting and Clinical Psychology, 59, 662669.

Hall, G. C. N., \& Hirschman, R. (1992). Sexual aggression against children: A conceptual perspective of etiology. Criminal Justice and Behavior, 19, 8-23.

Hall, G. C. N., \& Hirschman, R. (1996). A Quadripartite Model of Sexual Aggression. In Theory-based Assessment, Treatment and Prevention of Sexual Aggression (pp. 51-71). New York: Oxford University Press.

Hayashino, D. S., Wurtele, S. K., \& Klebe, K. J. (1995). Child molesters: An examination of cognitive factors. Journal of Interpersonal Violence, 10, 106116.

Heil, P., Ahlmeyer, S., \& Simons, D. (2003). Crossover sexual offenses. Sexual Abuse: A Journal of Research and Treatment, 15(4), 221-236.

Hudson, S. M., \& Ward, T. (1997). Intimacy, loneliness, and attachment style in sexual offenders. Journal of Interpersonal Violence, 12(3), 323-339.

Laws, D. R. (1989). Relapse prevention with sex offenders. New York: Guilford.

Levenson, J. S., Becker, J., \& Morin, J. W. (2008). The Relationship Between Victim Age and Gender Crossover Among Sex Offenders. Sexual Abuse: A Journal of Research and Treatment, 20(1), 43-60.

Lussier, P., Proulx, J., \& McKibben, A. (2001). Personality characteristics and adaptive strategies to cope with negative emotional states and deviant sexual fantasies in 
sexual aggressors. International Journal of Offender Therapy and Comparative Criminology, 45(4), 159-170.

Madsen, L., Parsons, S., \& Grubin, D. (2006). The relationship between the five-factor model and DSM personality disorder in a sample of child molesters. Personality and Individual Differences, 40(2), 227-236.

Marsa, F., O'Reilly, G., Carr, A., Murphy, P., O'Sullivan, M., Cotter, A., et al. (2004). Attachment styles and psychological profiles of child sex offenders in Ireland. Journal of Interpersonal Violence, 19(2), 228-251.

Marshall, W. L. (1989a). Intimacy, loneliness and sexual offenders. Behavior Research \& Therapy, 27(5), 491-503.

Marshall, W. L. (1989b). Invited essay: Intimacy, loneliness and sexual offenders. Behaviour Research and Therapy, 27, 491-503.

Marshall, W. L., \& Barbaree, H. E. (1990). An integrated theory of the etiology of sexual offending. In W. L. Marshall, D. R. Laws \& H. E. Barbaree (Eds.), Handbook of sexual assault: Issues, theories, and treatment of the offender (pp. 257-275). New York: Plenum.

Marshall, W. L., Cripps, E., Anderson, D., \& Cortoni, F. A. (1999). Self-Esteem and Coping Strategies in Child Molesters (Vol. 14, pp. 955-962).

Marshall, W. L., \& Eccles, A. (1991). Issues in clinical practice with sex offenders. Journal of Interpersonal Violence, 6, 68-93.

Marshall, W. L., Hamilton, K., \& Fernandez, Y. (2001). Empathy deficits and cognitive distortions in child molesters. Sexual Abuse: A Journal of Research and Treatment, 13, 123-130.

Marziano, V., Ward, T., Beech, A. R., \& Pattison, P. (2006). Identification of five fundamental implicit theoies underlying cognitive distortions in child abusers: a preliminary study. Psychology, Crime \& Law, 12(1), 97-105.

Millon, T. (1981). Disorders of Personality DSM-III: Axis II. New York: John Wiley \& Sons.

Millon, T., \& Davis, R. (1996). Disorders of Personality: DSM-IV \& Beyond (2nd ed.). Toronto, Canada: John Wiley \& Sons, Inc.

Millon, T., Grossman, S., Millon, C., Meagher, S., \& Ramnath, R. (2004). Personality Disorders in Modern Life (2nd ed.). Hoboken, New Jersey John Wiley \& Sons, Inc.

Mulder, R. (1997). Personality Disorders. Retrieved 1997, from http://www.moh.govt.nz/moh.nsf/Files/chap20/\$file/chap20.pdf.

Nugent, P. M., \& Kroner, D. G. (1996). Denial, response styles, and admittance of offenses among child molesters and rapists. Journal of Interpersonal Violence, $11,475-486$.

Paulhus, D. L. (1984). Two-component models of socially desirable responding. Journal of Personality and Social Psychology, 46, 598-609.

Paulhus, D. L. (2002). Socially desirable responding: The evolution of a construct. In H. Braun, D. N. Jackson \& D. E. Wiley (Eds.), The role of constructs in psychological and educational measurement (pp. 49-69). Mahwah, NJ: Lawrence Erlbaum.

Pervin, L. A. (1989). Personality: Theory and Research (5th ed.). New York: John Wiley \& Sons, Inc. 
Pithers, W. D. (1994). Process evaluation of a group therapy component designed to enhance sex offenders' empathy for sexual abuse survivors. Behaviour Research and Therapy, 32, 565-570.

Pretzer, J. L., \& Beck, A. T. (1996). A cognitive theory of personality disorders. In J. F. Clarkin \& M. F. Lenzenweger (Eds.), Major Theories of Personality Disorder (pp. 36-105). New York: Guilford Press.

Robertiello, G., \& Terry, K. J. (2007). Can we profile sex offenders? A review of sex offender typologies. Aggression and Violent Behavior, 12(5), 508-518.

Sawle, G. A., \& Kear-Colwell, J. (2001). Adult Attachment Style and Pedophilia: A Developmental Perspective. International Journal of Offender Therapy and Comparitive Criminology, 45, 32-50.

Simpson, A. I. F., Brinded, P. M., Fairley, N., Ladlaw, T. M., \& Malcolm, F. (2003). Does ethnicity affect need for mental health service among New Zealand prisoners. Australian and New Zealand Journal of Psychiatry, 37, 728-734.

Simpson, A. I. F., Brinded, P. M., Laidlaw, T. M., Fairley, N., \& Malcolm, F. (1999). The national study of psychiatric morbidity in New Zealand Prisons. Wellington: Department of Corrections.

Smallbone, S. W., Wheaton, J., \& Hourigan, D. (2003). Trait empathy and criminal versatility in sexual offenders. Sexual Abuse: A Journal of Research and Treatment, 12(1), 49-60.

Tan, L., \& Grace, R. C. (2008). Social Desirability and Sexual Offenders: A Review. Sexual Abuse: A Journal of Research and Treatment, 20(1), 61-87.

Vess, J., \& Skelton, A. (in press). Sexual and violent recidivism by offender type and actuarial risk: reoffending rates for rapists, child molesters and mixed-victim offenders. Psychology, Crime \& Law.

Ward, T. (2000). Sexual offenders' cognitive distortions as implicit theories. Aggression and Violent Behavior, 5, 491-507.

Ward, T. (2003). The explanation, assessment and treatment of child sexual abuse. International Journal of Forensic Psychology, 1(1), 10-25.

Ward, T., Gannon, T. A., \& Keown, K. (2006). Beliefs, values, and action: The judgment model of cognitive distortions in sexual offenders. Aggression and Violent Behavior, 11(4), 323-340.

Ward, T., Hudson, S. M., \& Marshall, W. L. (1995). Cognitive distortions and affective deficits in sex offenders: A cognitive deconstructionist interpretation. Sexual Abuse: Journal of Research and Treatment, 7(1), 67-83.

Ward, T., \& Keenan, T. (1999). Child molesters' implicit theories. Journal of Interpersonal Violence, 14, 821-838.

Ward, T., Keenan, T., \& Hudson, S. M. (2000a). Understanding cognitive, affective and intimacy deficits in sexual offenders: a developmental perspective. Aggression and Violent Behavior, 5(1), 41-62.

Ward, T., Keenan, T., \& Hudson, S. M. (2000b). Understanding cognitive, affective, and intimacy deficits in sexual offenders: A developmental perspective. Aggression and Violent Behavior, 5(1), 41-62.

Ward, T., Polaschek, D. L. L., \& Beech, A. R. (2005). Theories of Sexual Offending. Chichester, UK: Wiley.

Wilson, N. J. (2004). New Zealand high-risk offenders: who are they and what are the issues in their management and treatement? : The Department of Corrections. 
Wood, E., \& Riggs, S. (2008). Predictors of Child Molestation: Adult Attachment, Cognitive Distortions, and Empathy. Journal of Interpersonal Violence, 23(2), 259-275. 